\title{
The Neural Cell Adhesion Molecule Promotes Maturation of the Presynaptic Endocytotic Machinery by Switching Synaptic Vesicle Recycling from Adaptor Protein 3 (AP-3)- to AP-2-Dependent Mechanisms
}

\author{
Aparna Shetty, ${ }^{1 *}$ Vladimir Sytnyk, ${ }^{1,2 *}$ Iryna Leshchyns'ka, ${ }^{1,2 *}$ Dmytro Puchkov, ${ }^{1}$ Volker Haucke, ${ }^{3}$ \\ and Melitta Schachner ${ }^{1,4,5}$ \\ ${ }^{1}$ Zentrum für Molekulare Neurobiologie, Universität Hamburg, 20246 Hamburg, Germany, ${ }^{2}$ School of Biotechnology and Biomolecular Sciences, The \\ University of New South Wales, Sydney, New South Wales 2052, Australia, ${ }^{3}$ Leibniz Institut für Molekulare Pharmakologie and Freie Universität Berlin, \\ 13125 Berlin, Germany, ${ }^{4}$ Keck Center for Collaborative Neuroscience, Rutgers University, Piscataway, New Jersey 08854-8082, and ${ }^{5}$ Center for \\ Neuroscience, Shantou University Medical College, Shantou 515041, People's Republic of China
}

Newly formed synapses undergo maturation during ontogenetic development via mechanisms that remain poorly understood. We show that maturation of the presynaptic endocytotic machinery in CNS neurons requires substitution of the adaptor protein 3 (AP-3) with AP-2 at the presynaptic plasma membrane. In mature synapses, AP-2 associates with the intracellular domain of the neural cell adhesion molecule (NCAM). NCAM promotes binding of AP-2 over binding of AP-3 to presynaptic membranes, thus favoring the substitution of AP-3 for AP-2 during formation of mature synapses. The presynaptic endocytotic machinery remains immature in adult NCAM-deficient $(N C A M-/-)$ mice accumulating AP-3 instead of AP-2 and its partner protein AP180 in synaptic membranes and vesicles. NCAM deficiency or disruption of the NCAM/AP-2 complex in wild-type $(N C A M+/+)$ neurons by overexpression of AP-2 binding-defective mutant NCAM interferes with efficient retrieval of the synaptic vesicle v-SNARE synaptobrevin 2. Abnormalities in synaptic vesicle endocytosis and recycling may thus contribute to neurological disorders associated with mutations in NCAM.

\section{Introduction}

Cell adhesion molecules are not only important in development of the nervous system, but also in the adult regarding their ability to regulate synaptic plasticity. Prominent examples for their roles in synaptic functions are the neurexins and neuroligins (Sudhof, 2008; Shen and Scheiffele, 2010) and Ig superfamily molecules (Gerrow and El-Husseini, 2006) as well as the synapse-apposed extracellular matrix (Dityatev et al., 2010a,b). A contribution of adhesion molecules to influencing synaptic activity has been also rec-

\footnotetext{
Received May 23, 2013; revised Aug. 27, 2013; accepted Sept. 13, 2013.

Author contributions: A.S., V.S., and I.L. designed research; A.S., V.S., I.L., and D.P. performed research; A.S., V.S., I.L., and D.P. analyzed data; A.S., V.S., I.L., V.H., and M.S. wrote the paper.

This work was supported by the Deutsche Forschungsgemeinschaft (M.S., I.L., V.S.; SFB 958/ A01 to V.H.), the National Health and Medical Research Council (V.S.), the Rebecca L. Cooper Medical Research Foundation (V.S., I.L.), and the Li Ka Shing Foundation at Shantou University Medical College (M.S.). Melitta Schachner is a New Jersey Professor of Spinal Cord Research. We are grateful to Daria Guseva for help with neuromuscular junction preparation, Patricia Maness (University of North Carolina, Chapel Hill, NC) for full-length NCAM constructs, Gero Miesenböck (University of Oxford, Oxford, UK) for the VAMP2-pHluorin construct, Roger Tsien (University of California, San Diego, CA) for the Cherry construct, Reinhard Jahn (Max-Planck-Institute for Biophysics, Göttingen, Germany) for antibodies against synaptophysin, and Ute Eicke-Kohlmorgen, Achim Dahlmann, and Eva Kronberg for excellent technical assistance.

${ }^{*}$ A.S., V.S., and I.L. contributed equally to this work.

Correspondence should be addressed to either of the following: Melitta Schachner, Center for Molecular Neurobiology, University Hospital Hamburg-Eppendorf, Martinistrasse 52, 20246 Hamburg, Germany, E-mail: schachner@zmnh.unihamburg.de; or Vladimir Sytnyk, School of Biotechnology and Biomolecular Sciences, University of New South Wales, Sydney, NSW, 2052, Australia, E-mail:v.sytnyk@unsw.edu.au.

DOI:10.1523/JNEUROSCI.2192-13.2013

Copyright $\odot 2013$ the authors $\quad 0270-6474 / 13 / 3316828-18 \$ 15.00 / 0$
}

ognized in the novel context of synaptic vesicle (SV) exocytosis and endocytosis (Leshchyns'ka et al., 2006; Andreyeva et al., 2010).

To reach full competency in the maintenance of uninterrupted synaptic transmission, the machinery for synaptic vesicle recycling undergoes a complex process of maturation (Hannah et al., 1999; Bonanomi et al., 2006). One of the prominent features of this process is a switch in the adaptor proteins involved in synaptic vesicle endocytosis. In mature synapses, endocytosis of synaptic vesicle membranes is mediated at least in part by the adaptor protein 2 (AP-2; Kim and Ryan, 2009), which recruits clathrin to the presynaptic membrane to induce membrane internalization into clathrincoated vesicles. Several accessory proteins, such as AP180 (Koo et al., 2011) and endophilin (Hill et al., 2001), and surface membrane phospholipids, such as phosphatidylinositol-4,5-bisphosphate, influence recruitment of AP-2 to the membrane and subsequent clathrin-coated vesicle formation (Slepnev and De Camilli, 2000; Mousavi et al., 2004). Phospholipid-mediated binding of AP-2 to the plasma membrane is further potentiated by interactions of AP-2 with integral membrane proteins (Haucke and De Camilli, 1999). However, while AP-2 has been shown to bind to integral membrane proteins of synaptic vesicles, such as synaptotagmin (Zhang et al., 1994; Haucke and De Camilli, 1999), the integral membrane proteins that may recruit AP-2 to the presynaptic surface membrane remain unidentified.

AP-3 is another adaptor protein that localizes to endosomes but has also been found on purified synaptic vesicles (Takamori 
et al., 2006). In contrast to AP-2, AP-3 has been shown to mediate clathrin-independent vesicle formation (Shi et al., 1998) and function in immature synaptic vesicle recycling (Zakharenko et al., 1999). Although both AP-2 and AP-3 have been implicated in sorting of SV proteins (Kantheti et al., 1998; Nakatsu et al., 2004; Salazar et al., 2004; Seong et al., 2005), the molecular mechanisms that regulate switching between AP-3- and AP-2-dependent pathways are unknown (Hata et al., 2007).

Studies on neuromuscular junctions showed that deficiency in the neural cell adhesion molecule (NCAM), a member of the Ig superfamily, results in a predominantly immature form of neurotransmission that is sensitive to brefeldin $\mathrm{A}$, an inhibitor of AP-3 (and AP-1) function, suggesting that NCAM plays a role in synapse maturation (Polo-Parada et al., 2001, 2004; Hata et al., 2007). The mechanisms of NCAM-dependent synapse maturation remain, however, poorly understood. Here we show that NCAM interacts with AP-2 and promotes its binding to presynaptic membranes, thereby inducing a switch from immature AP-3- to mature AP-2-dependent synaptic vesicle recycling pathways in favor of AP-2-dependent mechanisms.

\section{Materials and Methods}

Antibodies and toxins. Rabbit polyclonal antibodies against the extracellular domain of mouse NCAM recognizing all NCAM isoforms (Leshchyns'ka et al., 2003; Westphal et al., 2010), mouse monoclonal antibody (D3) against an NCAM180-specific epitope in the intracellular domain of NCAM 180 (Pollerberg et al., 1985; Pollerberg et al., 1986; Persohn and Schachner, 1987), and rabbit polyclonal antibodies against the extracellular domain of L1 (Rolf et al., 2003) have been described previously. Mouse monoclonal antibodies against the intracellular domains of NCAM140 and NCAM180 (clone 5b8), SV2 (clone SV2), delta adaptin subunit of AP-3 (clone delta SA4), and the $\alpha 1$ subunit of $\mathrm{Na}, \mathrm{K}-$ ATPase (clone $\alpha 6 \mathrm{~F}$ ) were from the Developmental Studies Hybridoma Bank. Mouse monoclonal antibodies against the clathrin heavy chain (clone 23 , catalog \#610499), $\gamma$-adaptin subunit of AP1 (clone 88, catalog \#610385), $\alpha$-adaptin subunit of AP-2 (clone 8, catalog \#610501), neuronal adaptin-like protein beta ( $\beta$ NAP) subunit of AP-3 (clone 18, catalog \#610892), and PSD-95 (clone 16, catalog \#610495) were from BD Biosciences. Mouse monoclonal antibodies against AP180 (clone AP180-I, catalog \#A4825) and nonspecific rabbit Ig were from Sigma. Mouse monoclonal antibodies against SNAP25 (clone 71.2), rabbit polyclonal antibodies against syntaxin 1B (catalog \#110402), synaptotagmin 1 lumenal domain (catalog \#105102), and proton ATPase (catalog \#109002) were from Synaptic Systems (Göttingen, Germany). Mouse monoclonal antibodies against glyceraldehyde-3phosphate dehydrogenase (GAPDH; clone 6C5, catalog \#MAB374) were from Millipore Bioscience Research Reagents. Goat polyclonal antibodies against synaptophysin (catalog \#sc-7568), C terminus of NCAM (catalog \#sc-1507), and cysteine string protein (CSP; catalog \#sc-15951) were from Santa Cruz Biotechnology. Mouse monoclonal antibodies against vesicular acetylcholine transporter (VAChT; clone N6/38) were from UC Davis/NIH NeuroMab Facility. Rabbit polyclonal antibodies against synaptophysin were a generous gift from Reinhard Jahn (Max-Planck-Institute for Experimental Medicine, Göttingen, Germany). Secondary antibodies against rabbit, rat, goat, and mouse Ig coupled to horseradish peroxidase (HRP), Cy2, $\mathrm{Cy} 3$, or Cy5 were from Jackson ImmunoResearch Laboratories. Brefeldin A (BFA) was from Sigma. DL-AP5 and 6-cyano-7-nitroquinoxaline-2,3dione (CNQX) were from Tocris Bioscience.

DNA constructs and siRNAs. Constructs encoding NCAM140 and its intracellular domain were as described previously (Leshchyns'ka et al., 2003; $\mathrm{Li}$ et al., 2013). The intracellular domain of NCAM140 was mutated using the QuickChange II XL site-directed mutagenesis kit from Stratagene. Vesicle-associated membrane protein 2 (VAMP2)-pHluorin construct was a kind gift from G. Miesenböck (University of Oxford, Oxford, UK). AP-3 $\delta$ and control siRNAs were from Santa Cruz Biotechnology.

Animals. NCAM-/ - mice were provided by Harold Cremer (Cremer et al., 1994) and were inbred for at least nine generations onto the C57BL/6J background. These mice are deficient in expressing all iso- forms of NCAM. Animals for biochemical experiments were 2- to 3 -month-old NCAM+/+ and NCAM-/- littermates of either sex from heterozygous breeding. For some studies, younger mice were also used (as indicated in the text). To prepare cultures of hippocampal neurons, 1to 3-d-old C57BL/6J and NCAM-/- mice of either sex from homozygous breeding pairs were used.

Ethics statement. All experiments were conducted in accordance with the German and European Community laws on protection of experimental animals. All procedures used were approved by the responsible committees of The State of Hamburg and the University of New South Wales.

Preparation of brain tissue homogenates. Homogenates of brains were prepared as described previously (Leshchyns'ka et al., 2006) using a Potter homogenizer in HOMO buffer $\left(1 \mathrm{mM} \mathrm{MgCl}_{2}, 1 \mathrm{~mm} \mathrm{CaCl}, 1 \mathrm{~mm}\right.$ $\mathrm{NaHCO}_{3}, 5$ mm Tris, pH 7.4) containing $0.32 \mathrm{~m}$ sucrose (HOMO A).

Isolation of synaptosomes. Synaptosomes were isolated from homogenates as described previously (Kleene et al., 2001). All steps were performed at $4^{\circ} \mathrm{C}$. Briefly, homogenates were centrifuged at $1400 \times g$ for 10 min. The supernatant and pellet were resuspended separately in HOMO A buffer and centrifuged for $10 \mathrm{~min}$ at $700 \times \mathrm{g}$. The resulting supernatants were combined and centrifuged at $17,500 \times g$ for $15 \mathrm{~min}$. The pellet was resuspended in HOMO A buffer and applied on top of a step gradient with interfaces of $0.65,0.85,1$, and $1.2 \mathrm{M}$ sucrose in HOMO buffer. The $700 \times g$ pellets were combined, adjusted to $1 \mathrm{~m}$ sucrose in HOMO buffer and layered on $1.2 \mathrm{~m}$ sucrose in HOMO buffer. HOMO A buffer was applied on the top of the step gradient. Crude synaptosomal fractions were collected at the $1 / 1.2 \mathrm{~m}$ interface after centrifugation for $2 \mathrm{~h}$ at $100,000 \times g$ and combined. This crude synaptosomal fraction was again adjusted to $1 \mathrm{~m}$ sucrose and layered on top of $1.2 \mathrm{~m}$ sucrose in HOMO buffer. HOMO A buffer was applied on top of the step gradient. After centrifugation for $2 \mathrm{~h}$ at $100,000 \times g$, synaptosomes were collected at the 1/1.2 $\mathrm{m}$ interface, resuspended in HOMO A buffer, and pulled down by centrifugation for $30 \mathrm{~min}$ at $100,000 \times g$

Isolation of the soluble synaptic fraction. Soluble synaptic fraction was obtained as described previously (Whittaker and Barker, 1972). All steps were performed at $4^{\circ} \mathrm{C}$. Brain homogenates were centrifuged at $1000 \times g$ for $11 \mathrm{~min}$ in HOMO A buffer. The supernatant and pellet were resuspended separately in HOMO A buffer and centrifuged for $11 \mathrm{~min}$ at $1000 \times g$. The resulting supernatants were combined and centrifuged at $17,500 \times g$ for $1 \mathrm{~h}$. The pellet was lysed in ice cold water $(2 \mathrm{ml} / \mathrm{g}$ of original tissue) by repeated pipetting followed by centrifugation at $12,000 \times g$ for $30 \mathrm{~min}$. The resulting supernatant was layered on a sucrose step gradient of $0.4,0.6,0.8,1$, and $1.2 \mathrm{M}$ sucrose in HOMO buffer and centrifuged at $63,000 \times g$ for $2 \mathrm{~h}$. The clear band obtained on top of the gradient was collected as a soluble synaptic fraction.

Isolation of synaptic plasma membranes and synaptic vesicular organelles. Synaptic plasma membranes were isolated from synaptosomes as described previously (Leshchyns'ka et al., 2006). Unless stated otherwise, all steps were performed at $4^{\circ} \mathrm{C}$. Briefly, synaptosomes were lysed by diluting them in nine volumes of ice-cold $\mathrm{H}_{2} \mathrm{O}$ and then immediately adjusted by $1 \mathrm{~m}$ HEPES, pH 7.4 to a final concentration of 7.5 mM HEPES. After incubation on ice for $30 \mathrm{~min}$, the mixture was centrifuged at $100,000 \times g$ for $20 \mathrm{~min}$. The resulting pellet contained synaptic plasma membranes. This fraction was highly enriched in the plasma membrane marker Na, K-ATPase and negative for Golgi and trans-Golgi marker $\gamma$-adaptin (data not shown). The supernatant was centrifuged at $230,000 \times g$ for $1 \mathrm{~h}$. The resulting pellet contained synaptic vesicular organelles.

Isolation of neuromuscular junctions. Neuromuscular junctions were isolated as described previously (Whelchel et al., 2004). Surgically removed diaphragms, soleus muscle, and biceps femoris muscles were homogenized in $255 \mathrm{~mm}$ sucrose, $1 \mathrm{~mm}$ EDTA, and 20 mM HEPES buffer on ice. The homogenate was centrifuged at $1000 \times g$ to obtain a supernatant, which was centrifuged at $10,000 \times g$. All centrifugation steps were performed at $4^{\circ} \mathrm{C}$. The resulting supernatant was centrifuged at $250,000 \times g$ for $1 \mathrm{~h}$. The pellet enriched in neuromuscular junctions (NMJs) was used for Western blot analysis.

Recombinant protein production. Nonmutated and mutated His6 tagged intracellular domains of NCAM140 were expressed in Escherichia 
coli and purified using Ni-NTA beads as described previously (Bodrikov et al., 2005; Chernyshova et al., 2011).

Analysis of AP-2, clathrin, and AP-3 binding to synaptic plasma membranes. Recruitment of AP-2, AP-3 and clathrin to synaptic membranes isolated as described above, in Isolation of synaptic plasma membranes and synaptic vesicular organelles, was analyzed using a protocol described by Krauss et al. (2003) with the following modifications. Synaptic plasma membranes were incubated in $0.1 \mathrm{M} \mathrm{Na}_{2} \mathrm{CO}_{3}$ for $15 \mathrm{~min}$ at $37^{\circ} \mathrm{C}$ to strip peripheral proteins. The soluble fraction of brain tissue containing cytosol, which was isolated from the $N C A M+/+$ brain homogenates by centrifugation at $100,000 \times g$ for $1 \mathrm{~h}$ and collecting the supernatant, was used as a source of endogenous AP-2, clathrin, and AP-3. Recruitment experiments were performed in a total volume of $500 \mu$ l containing $100 \mu \mathrm{g} / \mathrm{ml}$ synaptic membrane and $0.5-1 \mathrm{mg} / \mathrm{ml}$ brain cytosol diluted in cytosolic buffer [containing the following (in mM): 2.5 HEPES-KOH, $\mathrm{pH}$ 7.4, $25 \mathrm{KCl}, 2.5 \mathrm{Mg}$ acetate, $5 \mathrm{EGTA}, 150 \mathrm{~K}$-glutamate]. The reaction mixture was incubated for $15 \mathrm{~min}$ at $37^{\circ} \mathrm{C}$ and centrifuged at $100,000 \times$ $g$ for $30 \mathrm{~min}$. The pellet was washed in $500 \mu \mathrm{l}$ of cytosolic buffer by thorough resuspension and centrifugation at $100,000 \times g$ for $30 \mathrm{~min}$ and analyzed by immunoblotting. When indicated, the synaptic plasma membrane and cytosol were preincubated with BFA $(200 \mu \mathrm{M})$ or intracellular domains of NCAM140 $(55 \mu \mathrm{M})$ for $15 \mathrm{~min}$ at $37^{\circ} \mathrm{C}$ before combining them.

Isolation and purification of synaptic vesicles. Synaptic vesicles were isolated as described previously (Huttner et al., 1983; Thoidis et al., 1998). All steps were performed at $4^{\circ} \mathrm{C}$ with cold buffers. Briefly, 5 to 10 adult mouse brains were homogenized in $320 \mathrm{~mm}$ sucrose/ 4 mM HEPES, $\mathrm{pH} 7.4$, and centrifuged at $1100 \times g$ for $10 \mathrm{~min}$. The resulting supernatant and pellet, resuspended in $0.32 \mathrm{~m}$ sucrose/4 mM HEPES, pH 7.4, were centrifuged for $15 \mathrm{~min}$ at $9200 \times g$ and $10,500 \times g$, respectively. The pellets (crude synaptosomal fraction) were lysed by diluting them in nine volumes of ice-cold distilled water and immediately adjusted by $1 \mathrm{M}$ HEPES, pH 7.4, to a final concentration of 7.5 mM HEPES. After incubation on ice for $30 \mathrm{~min}$, the lysate was centrifuged at $25,500 \times g$ for $20 \mathrm{~min}$. The supernatant was then centrifuged for $2 \mathrm{~h}$ at $130,000 \times g$. The resulting pellet representing a crude synaptic vesicle fraction was resuspended in $30 \mathrm{~mm}$ sucrose/4 mM HEPES, pH 7.4, homogenized by passing through a 25 gauge needle, loaded on a continuous gradient of $50-800$ mM sucrose $/ 4 \mathrm{~mm}$ HEPES, $\mathrm{pH} 7.4$, and centrifuged at $100,000 \times g$ for $5 \mathrm{~h}$. A broad band in the $200-400 \mathrm{~mm}$ sucrose region containing synaptic vesicles was collected and pooled by centrifugation at $250,000 \times g$ for $2 \mathrm{~h}$. The pellet, containing synaptic vesicles, was resuspended in $30 \mathrm{~mm}$ sucrose/4 mM HEPES, pH 7.4. Western blot analysis confirmed that it was highly enriched in the synaptic vesicle marker synaptophysin and negative for plasma membrane marker $\mathrm{Na}, \mathrm{K}$-ATPase. To obtain highly purified synaptic vesicles, synaptic vesicles isolated in a sucrose gradient were incubated in $30 \mathrm{~mm}$ sucrose $/ 4 \mathrm{~mm}$ HEPES, $\mathrm{pH}$ 7.4, with antibodies against synaptophysin or CSP and precipitated with protein A agarose beads. The beads were then boiled in Laemmli buffer and the eluted material was used for Western blot analysis.

Coimmunoprecipitation. Coimmunoprecipitation experiments were performed essentially as described previously (Leshchyns'ka et al., 2006; Westphal et al., 2010). Samples containing $1 \mathrm{mg}$ of total protein were lysed for $40 \mathrm{~min}$ at $+4^{\circ} \mathrm{C}$ with lysis buffer, $\mathrm{pH} 7.5$, containing $50 \mathrm{~mm}$ Tris - $\mathrm{HCl}, 150 \mathrm{~mm} \mathrm{NaCl}, 1 \%$ Nonidet P-40, $1 \mathrm{~mm} \mathrm{Na}_{2} \mathrm{P}_{2} \mathrm{O}_{7}, 1 \mathrm{~mm} \mathrm{NaF}, 2 \mathrm{~mm}$ $\mathrm{Na}_{3} \mathrm{VO}_{4}, 0.1 \mathrm{~mm}$ PMSF, 2 mm EDTA and EDTA-free protease inhibitor cocktail (Roche Diagnostics). Lysates were centrifuged for $15 \mathrm{~min}$ at $20,000 \times g$ at $4^{\circ} \mathrm{C}$. Supernatants were cleared with protein A/G-agarose beads (Santa Cruz Biotechnology) applied for $3 \mathrm{~h}$ at $4^{\circ} \mathrm{C}$ and incubated with NCAM polyclonal antibodies or nonspecific rabbit IgG applied overnight at $4^{\circ} \mathrm{C}$. NCAM-antibody complexes were then precipitated with protein $\mathrm{A} / \mathrm{G}$-agarose beads applied for $1 \mathrm{~h}$ at $4^{\circ} \mathrm{C}$. Beads were washed three times with lysis buffer and two times with TBS and used for Western blot analysis. The approximate percentage of AP-2 molecules bound to NCAM in synaptosomes $(\mathrm{P})$ was quantified as described previously (Santuccione et al., 2005): $\mathrm{P}=\left(\mathrm{AP}-2_{\mathrm{IP}} / \mathrm{AP}-2_{\text {input }}\right)$ * $\left(\mathrm{NCAM}_{\text {input }} / \mathrm{NCAM}_{\mathrm{IP}}\right) * 100 \%$, where $\mathrm{NCAM}_{\text {input }}$ and $\mathrm{NCAM}_{\mathrm{IP}}$ are labeling intensities of NCAM in the input material and NCAM immunoprecipitates, respectively, and $\mathrm{AP}-2_{\text {input }}$ and $\mathrm{AP}-2_{\mathrm{IP}}$ are labeling intensities of AP-2 in the input material and NCAM immunoprecipitates, respectively.

When interactions were analyzed in transfected CHO KO1 or HEK293 cells, cells were lysed $48 \mathrm{~h}$ after transfection with the lysis buffer and coimmunoprecipitation was analyzed as described above. In some experiments, live HEK293 cells were preincubated with NCAM polyclonal antibodies for $3 \mathrm{~h}$ in a $\mathrm{CO}_{2}$ incubator to label surface NCAM only. Cells were then washed two times with ice-cold PBS and lysed for $30 \mathrm{~min}$ on ice with the lysis buffer. NCAM-containing complexes were then precipitated with protein A/G-agarose beads as described above. Similar results were obtained with both approaches.

Western blot analysis. Proteins were separated by $4-12 \%$ or $8 \%$ SDSPAGE and electroblotted to nitrocellulose transfer membrane (PROTRAN; Schleicher and Schuell; Bodrikov et al., 2005). Immunoblots were incubated with appropriate primary antibodies followed by incubation with HRP-labeled secondary antibodies and visualized using ECL Western blotting reagents (GE Healthcare) or SuperSignal West Dura Extended Duration reagents (Pierce) on BIOMAX films (Sigma). Molecular weight markers were prestained protein standards from BioRad. All preparations were performed at least three times. The chemiluminescence quantification was performed using TINA 2.09 software (University of Manchester, Manchester, UK) or Image J (National Institute of Health, Bethesda, MD).

Cultures of hippocampal neurons and $\mathrm{CHO}$ and HEK cells. Cultures of hippocampal neurons were prepared from 1- to 3-d-old mice as described previously (Puchkov et al., 2011). Neurons were grown for 14-21 $\mathrm{d}$ in Neurobasal A medium (Invitrogen) supplemented with 2\% B-27 (Invitrogen), glutamine (Invitrogen) and FGF-2 (2 ng/ml; R\&D Systems) on glass coverslips coated with poly-L-lysine $(100 \mu \mathrm{g} / \mathrm{ml})$. When indicated, neurons were transfected $12 \mathrm{~d}$ after plating with DNA constructs or DNA constructs together with siRNA using Lipofectamine 2000 (Invitrogen) combined with CombiMag (OzBiosciences) according to the manufacturers' instructions.

$\mathrm{CHO} \mathrm{KO} 1$ and HEK293 cells were maintained in the presence of $10 \%$ fetal calf serum in Glasgow medium or DMEM, respectively. Both cells lines were transfected using Lipofectamine with Plus reagent (Invitrogen) following the manufacturer's instructions.

Loading and unloading of FM dyes in synaptic boutons. Dynasore (80 $\mu \mathrm{M})$ and brefeldin $\mathrm{A}(10 \mu \mathrm{g} / \mathrm{ml})$ were applied to cultured neurons for $2 \mathrm{~h}$ in the culture medium in a $\mathrm{CO}_{2}$ incubator. All procedures then were performed at room temperature in the presence of $10 \mu \mathrm{M}$ CNQX and 50 $\mu \mathrm{M}$ AP- 5 to prevent recurrent activation elicited by AMPA and NMDA receptors, respectively. Neurons were washed briefly in modified Tyrode solution containing the following (in $\mathrm{mM}$ ): $150 \mathrm{NaCl}, 4 \mathrm{KCl}, 1 \mathrm{MgCl}_{2}, 10$ glucose, $10 \mathrm{HEPES}$, and $1 \mathrm{CaCl}_{2}, \mathrm{pH}$ 7.4. Synaptic boutons of neurons were loaded with FM1-43FX (15 $\mu$; Invitrogen) applied for $90 \mathrm{~s}$ in 47 $\mathrm{mm} \mathrm{K}^{+}$solution (modified Tyrode solution containing equimolar substitution of $\mathrm{KCl}$ for $\mathrm{NaCl}$; Leshchyns'ka et al., 2006; Andreyeva et al., 2010). Neurons were then used for the analysis of FM1-43 release or washed with modified Tyrode solution and fixed for $15 \mathrm{~min}$ in $4 \%$ formaldehyde in PBS, pH 7.4, to be used for the analysis of FM1-43 uptake. Unloading of synaptic boutons, that is, release of the dye after loading, was achieved by application of $47 \mathrm{mM} \mathrm{K}^{+}$to the cultures (Virmani et al., 2003). Unloading rate was monitored with time by acquiring images using LSM510 with $1 \mathrm{~s}$ interval.

Immunofluorescence labeling of recycling synaptic vesicles. Recycling synaptic vesicles were labeled by incubating live neurons with antibodies against the lumenal domain of synaptotagmin 1 (Synaptic Systems) applied in culture medium containing $47 \mathrm{mM} \mathrm{K}^{+}$for $5 \mathrm{~min}$ in a $\mathrm{CO}_{2}$ incubator. Neurons were then washed with PBS, $\mathrm{pH} 7.4$, fixed for $15 \mathrm{~min}$ in $4 \%$ formaldehyde in PBS, permeabilized with $0.25 \%$ Triton X-100 in PBS for $5 \mathrm{~min}$, and blocked with 1\% BSA in PBS for $20 \mathrm{~min}$. Synaptotagmin 1 antibodies were then visualized by corresponding secondary antibodies applied for $45 \mathrm{~min}$ in 1\% BSA in PBS.

Immunofluorescence labeling of fixed neurons. Immunolabeling was performed as described previously (Sytnyk et al., 2002). All steps were performed at room temperature, and all antibodies were applied in $1 \%$ BSA in PBS, pH 7.4. Neurons were fixed for $15 \mathrm{~min}$ in $4 \%$ formaldehyde in PBS. This fixation procedure does not permeabilize membranes (Syt- 
nyk et al., 2002). Neurons were then blocked with 1\% BSA in PBS for 20 min. NCAM at the cell surface was detected with polyclonal antibodies against NCAM extracellular domain applied for $30 \mathrm{~min}$ followed by corresponding secondary antibodies applied for $30 \mathrm{~min}$. Then neurons were postfixed for $5 \mathrm{~min}$ in $2 \%$ formaldehyde in PBS, washed with PBS, permeabilized with $0.25 \%$ Triton X-100 in PBS for 5 min, blocked with $1 \%$ BSA in PBS for $20 \mathrm{~min}$, and treated with primary antibodies against indicated in the text intracellular proteins for $2 \mathrm{~h}$ followed by corresponding secondary antibodies applied for $45 \mathrm{~min}$. Coverslips were embedded in Aqua-Poly/Mount (Polysciences). Images were acquired at room temperature using a confocal laser scanning microscope LSM510 (Zeiss).

FM uptake quantification. In fixed and permeabilized neurons, labeling with SV2 antibodies was used to identify synaptic boutons that were defined as SV2 accumulations with a mean intensity of at least 30\% higher than background. The background was defined as the mean intensity of pixels in the square $30 \times 30$ pixel area located in the vicinity of the synaptic bouton in the part of the image devoid of synaptic boutons (Leshchyns'ka et al., 2006). Synaptic boutons were outlined using a threshold function of the ImageJ software. Within the outlines, mean intensities of the FM dye were measured and expressed in arbitrary units defined as 8 bit pixel values of the gray scale image. In each experiment, images were acquired using identical settings and the same threshold was used for all groups.

Electron microscopic analysis of HRP uptake. Cultured hippocampal neurons were preincubated with HRP $(10 \mathrm{mg} / \mathrm{ml})$ in modified Tyrode solution for $5 \mathrm{~min}$ and stimulated with $47 \mathrm{mM} \mathrm{K}^{+}$solution containing HRP $(10 \mathrm{mg} / \mathrm{ml})$ for $90 \mathrm{~s}$. Following stimulation, cultures were washed briefly with modified Tyrode solution containing HRP and fixed in 3\% glutaraldehyde in PBS for $20 \mathrm{~min}$. Where indicated, neurons were pretreated with BFA $(10 \mu \mathrm{g} / \mathrm{ml})$ applied for $2 \mathrm{~h}$ in the culture medium in a $\mathrm{CO}_{2}$ incubator. Cultures were washed in PBS, and HRP was visualized by incubating cultures for $25 \mathrm{~min}$ in $3,3^{\prime}$-diaminobenzidine tetrahydrochloride $(0.75 \mathrm{mg} / \mathrm{ml})$ in $0.05 \mathrm{M}$ Tris- $\mathrm{HCl}, \mathrm{pH} 7.6$, containing $0.01 \%$ hydrogen peroxide (Neale et al., 1999). Neurons were washed in PBS, postfixed with $1 \% \mathrm{OsO}_{4}$ for $1 \mathrm{~h}$ at room temperature, washed with distilled water, stained en bloc with $1 \%$ aqueous solution of uranyl acetate, dehydrated, and embedded into Epoxy resin. Sections ( $60 \mathrm{~nm}$ thick) were viewed with a Zeiss EM10C transmission electron microscope. Synaptic terminals were photographed with a digital camera at 30,000 $\times$ magnification. The analysis was performed in a blinded manner, i.e., the observer did not know the genotype and treatments of the individual samples. Vesicles were considered as HRP positive if the intensity of HRP labeling in the vesicle lumen was at least three times higher when compared to the background labeling of nonvesicular compartments in the presynaptic terminal. Synapses with asymmetric PSDs presumably representing excitatory synapses were taken for analysis. At least 100 synapses from four to six individual cultures were analyzed per experimental group. Regular shaped vesicles smaller than $50 \mathrm{~nm}$ in diameter and $2000 \mathrm{~nm}^{2}$ in crosssection area were counted as synaptic vesicles. All other larger vesicles observed in synaptic terminals were classified as endosomes of different sizes. The cross-section area of vesicles was measured using the UTHSCSA Image Tool program (University of Texas, San Antonio, TX).

pHluorin fluorescence quantification. During recordings, live neurons transfected with VAMP2-pHluorin were maintained at room temperature in modified Tyrode solution [containing the following (in $\mathrm{mm}$ ): 150 $\mathrm{NaCl}, 4 \mathrm{KCl}, 1 \mathrm{MgCl}_{2}, 10$ glucose, $10 \mathrm{HEPES}$, and $1 \mathrm{CaCl}_{2}, \mathrm{pH}$ 7.4]. Neurons were cotransfected with cherry fluorescent protein to improve identification of transfected neurons. When indicated, neurons were stimulated with $47 \mathrm{~mm} \mathrm{~K}^{+}$buffer (modified Tyrode solution containing equimolar substitution of $\mathrm{KCl}$ for $\mathrm{NaCl}$; Virmani et al., 2003). Alternatively, neurons were stimulated with $1 \mathrm{~ms}$ bipolar current pulses at $10 \mathrm{~Hz}$ to yield fields of $10 \mathrm{~V} / \mathrm{cm}$. All procedures were performed in the presence of $10 \mu \mathrm{M}$ CNQX and $50 \mu \mathrm{M}$ AP-5 to prevent recurrent activation elicited by AMPA and NMDA receptors, respectively. Changes in fluorescence were monitored with time by acquiring images using a laser scanning microscope LSM510 (Zeiss) with a $1 \mathrm{~s}$ interval. With these recorded time series, synaptic boutons were identified as accumulations of pHluorin fluorescence that appeared following the stimulation and were at least
$30 \%$ brighter in intensity than the background pHluorin fluorescence before stimulation. Clusters of pHluorin fluorescence were outlined in ImageJ software at the time point when pHluorin fluorescence reached the maximum following the stimulation. These outlines were then used to measure pHluorin fluorescence intensity on all images that were recorded before and after stimulation.

\section{Results}

\section{Subsynaptic targeting of clathrin, AP-2 and AP-3 is abnormal} in NCAM-/- CNS synapses

Studies on the neuromuscular junction have shown immaturity of the synaptic vesicle recycling machinery in NCAM-/- mice (Polo-Parada et al., 2001; 2004), suggesting abnormalities in synaptic vesicle genesis. Hence, we started our work by analyzing the molecular machinery responsible for synaptic vesicle formation in NCAM-/- versus NCAM+/+ CNS synapses. The AP-2 and AP-3 adaptor proteins are responsible for the clathrin-dependent retrieval of synaptic vesicle membrane from the surface plasma membrane following synaptic vesicle exocytosis and for clathrinindependent synaptic vesicle formation from intracellular organelles of endosomal origin, respectively (Fig. 1A; Faúndez et al., 1998; Shi et al., 1998; Hao et al., 1999; Zakharenko et al., 1999; Ford et al., 2001). In cultured NCAM+/+ hippocampal neurons, clusters of the integral synaptic vesicle membrane protein synaptophysin overlapped with accumulations of AP-2 and AP-3 and NCAM (Fig. 1 B, C). Synaptophysin positive accumulations of AP-2 and AP-3 were often apposed to clusters of the postsynaptic protein PSD95 (data not shown), confirming that AP-2 and AP-3 accumulate in functional excitatory synapses. Thus, AP-2- and AP-3-dependent synaptic vesicle generating pathways can coexist in $N C A M+/+$ synaptic boutons.

Next, we compared the levels of clathrin and adaptor proteins in brains and synaptosomes from brains of $N C A M+/+$ mice and mice deficient in all NCAM isoforms (NCAM-/-; Cremer et al., 1994). Synaptosomes were fractionated to obtain the cytosolic fraction, plasma membranes, and the complete pool of vesicular organelles including synaptic vesicles. Levels of AP-2, clathrin, and the exclusively neuronal presynaptic adaptor protein AP180, which cooperates with AP-2 in clathrin-dependent synaptic vesicle endocytosis (Zhang et al., 1998; Hao et al., 1999), were slightly increased in NCAM-/- versus NCAM+/+ synaptosomes (Fig. 1E) corresponding to the elevated expression of these proteins in NCAM-/- brains (Fig. 1D). Despite their elevated expression, the levels of clathrin, AP-2, and AP180 were decreased by $\sim 50 \%$ in synaptic plasma membranes and synaptic vesicular organelles from $N C A M-/-$ versus $N C A M+/+$ brains (Fig. 1E). These observations suggest that recruitment of clathrin, AP-2 and AP180 from the cytoplasm to the synaptic plasma membrane and formation of AP-2/AP180/clathrin-coated vesicles are reduced presynaptically in $N C A M-/-$ synapses. In accordance with this idea, the levels of AP-2, AP180, and clathrin were increased in the cytosol of NCAM-/- versus NCAM+/+ synaptosomes (Fig. 1E), indicating reduced recruitment of these proteins from the cytoplasm to the plasma membrane and to vesicular compartments.

In contrast, the levels of AP-3 and those of another adaptor protein AP-1 involved in vesicle budding from the TGN and/ or endosomes were increased in NCAM-/- synaptosomes and in synaptic organelles isolated from NCAM-/- synaptosomes (Fig. 1E). Furthermore, despite the overall increased levels of AP-3 in NCAM-/- synaptosomes, its levels were reduced in cytosol prepared from these synaptosomes (Fig. 1E), again suggesting increased recruitment of AP-3 to vesicular organelles. In 
A

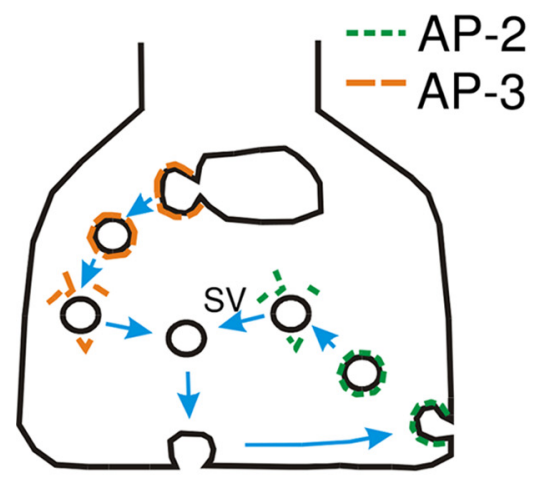

C

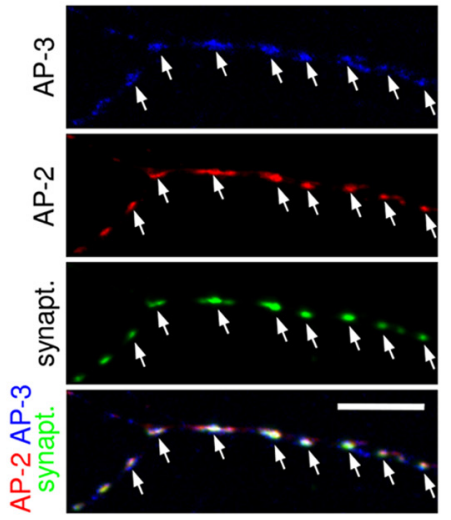

B
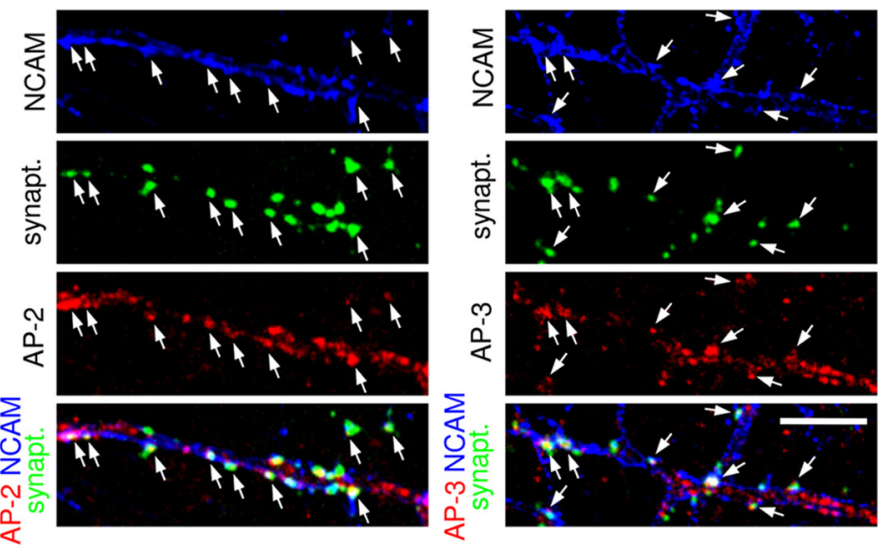

D

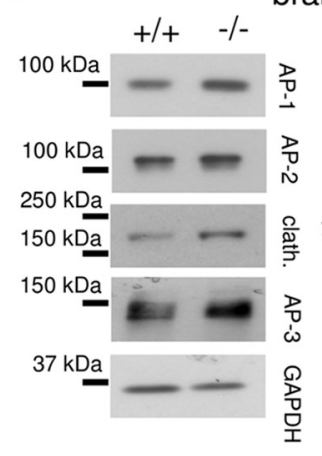

brain homogenates

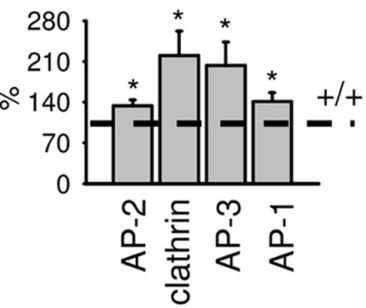

E

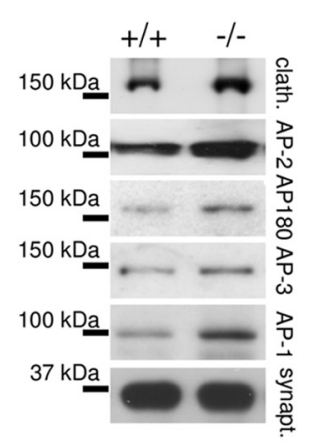

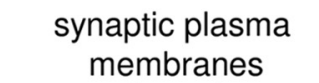

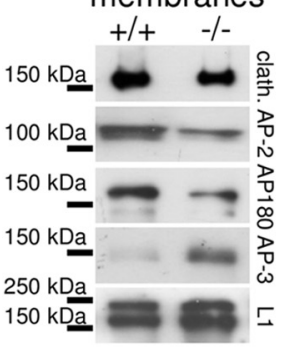

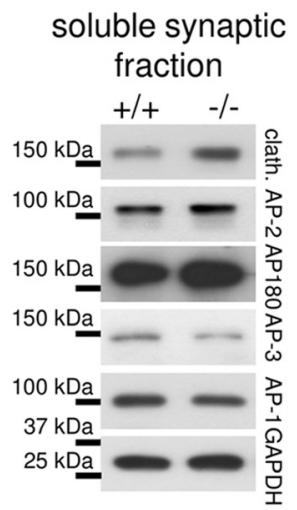

\author{
synaptic vesicular \\ organelles
}
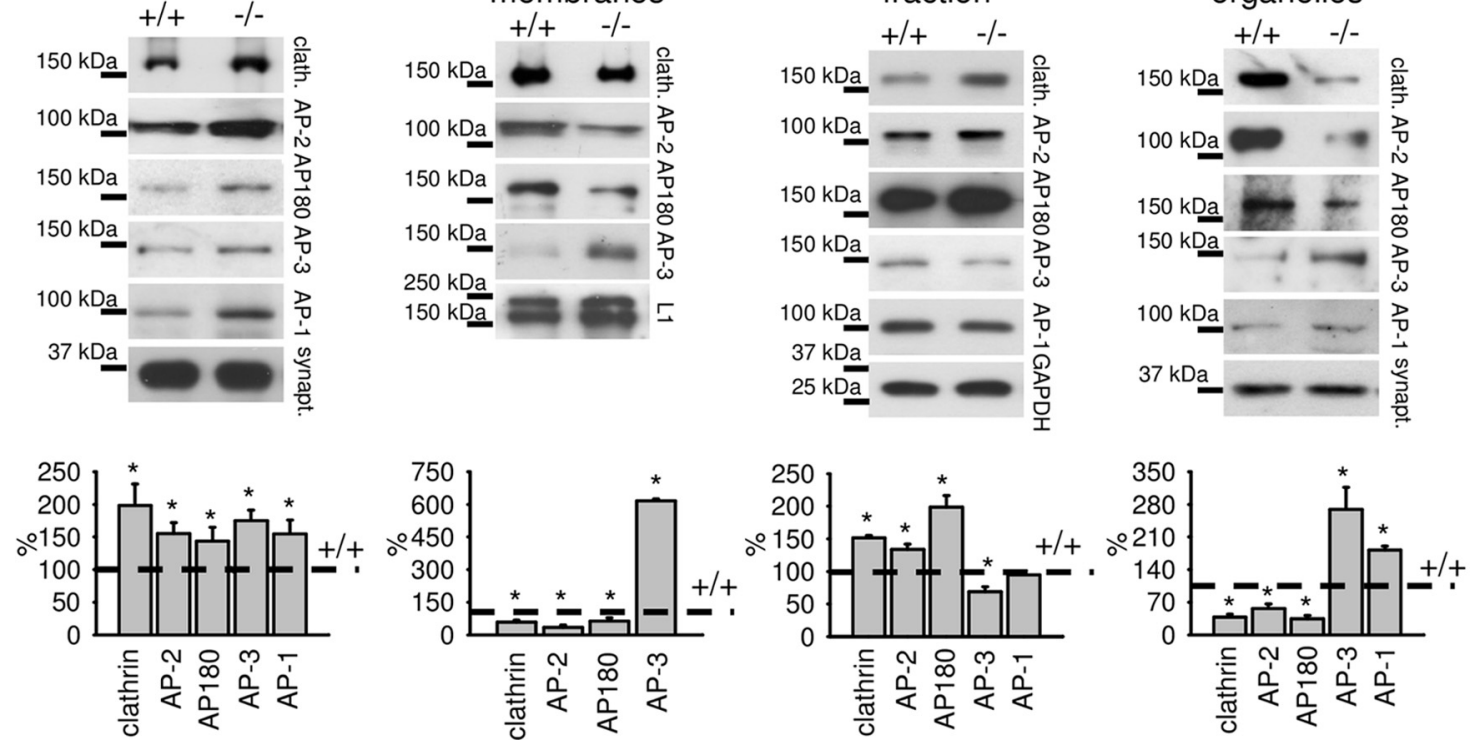

Figure 1. Targeting of AP-2, AP180, and clathrin to the synaptic plasma membrane is reduced in NCAM-/- synapses. A, A scheme showing the subsynaptic localization of the AP-2 and AP-3 adaptor proteins and their role in synaptic vesicle formation. Synaptic vesicles are formed via AP-2/clathrin mediated endocytosis from the presynaptic surface membrane or via AP-3 mediated budding from endosomes. $\boldsymbol{B}$, Cell surface NCAM was labeled by indirect immunofluorescence of formaldehyde-fixed hippocampal neurons maintained in culture for $12 \mathrm{~d}$. Neurons were then permeabilized and labeled with antibodies against synaptophysin and AP-2 or AP-3. NotethatNCAM-and synaptophysin-positive clusters colocalize with AP-2 and AP-3 accumulations (arrows). C, Hippocampal neurons maintained in culture for 12 d were colabeled with antibodies against synaptophysin, AP-2, and AP-3. Note overlapping accumulations of AP-2 and AP-3, which colocalize with synaptophysin-positive clusters. D, E, NCAM +/+ and NCAM - / brain homogenates $(\boldsymbol{D})$ and synaptosomes, synaptic plasma membranes, soluble fraction from synaptosomes, and synaptic vesicular organelles $(\boldsymbol{E})$ were probed by Western blot with the indicated antibodies. Note reduced levels of AP-2, AP180 and clathrin, and increased levels of AP-3 in NCAM - / - synaptic plasma membranes and vesicular organelles. Synaptophysin served as a loading control for synaptosomes and vesicular organelles, while labeling with antibodies against the plasma membrane associated cell adhesion molecule L1 and cytosolic marker protein GAPDH verified equal loading in synaptic plasma membranes and soluble fraction/brain homogenates, respectively. Graphs show quantitation of blots. Mean levels + SEM in NCAM - / - mice normalized to the levels in NCAM +/+ mice set to $100 \%$ (dashed lines) are shown. ${ }^{*} p<0.05$, paired $t$ test (compared to $N C A M+/+; n=3$ ). Scale bars: $10 \mu \mathrm{m}$. 
A
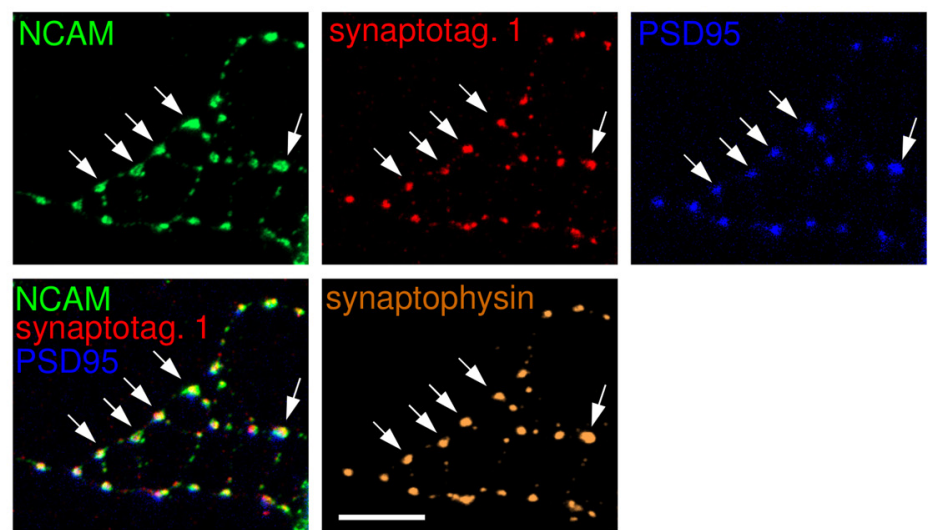

B
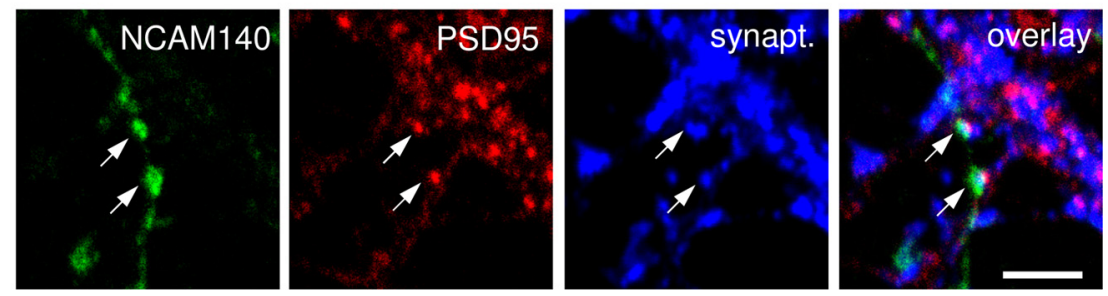

C
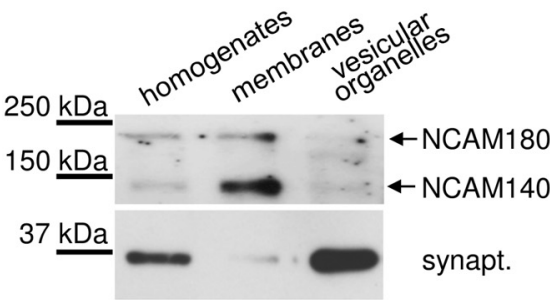

synapt.

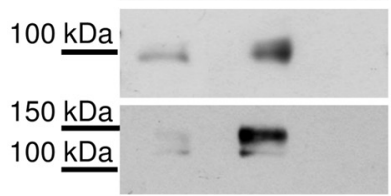

PSD95

$\mathrm{Na}, \mathrm{K}$

ATPase

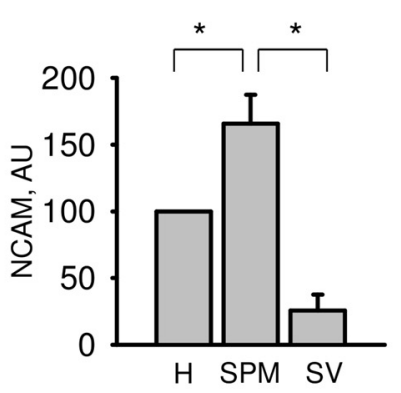

D

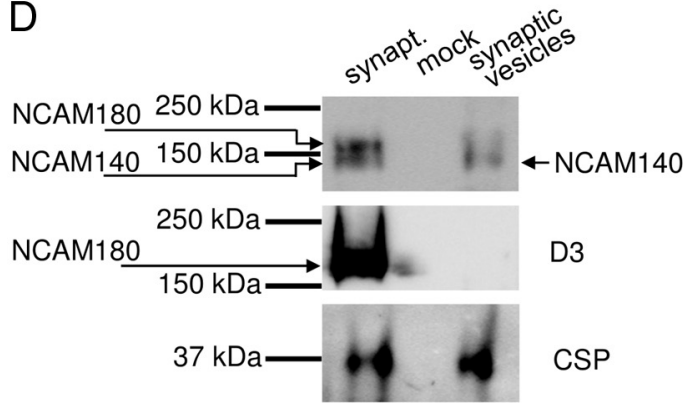

Figure 2. NCAM accumulates in the presynaptic membrane. $\boldsymbol{A}$, Recycling synaptic vesicles were labeled by incubating live $N C A M+/+$ neurons with antibodies against the lumenal domain of synaptotagmin 1 applied in the culture medium containing $47 \mathrm{~mm} \mathrm{~K}^{+}$. Neurons were then fixed with formaldehyde and colabeled with antibodies against NCAM, PSD95 and synaptophysin. Note the clusters of NCAM overlapping with accumulations of synaptotagmin 1 and synaptophysin apposed to PSD95 clusters (arrows). B, Formaldehyde-fixed NCAM - / - neurons transfected with NCAM140 were labeled with antibodies against NCAM, the presynaptic marker protein synaptophysin and the postsynaptic marker protein PSD95. An axon of an NCAM140 transfected neuron is shown. Note that accumulations of synaptophysin colocalize with accumulations of NCAM140 in NCAM- / - neuron transfected with NCAM140 abutting onto NCAM - / - neurons (arrows). NCAM140/synaptophysin accumulations are apposed to PSD95 clusters. C, Brain homogenates, synaptic plasma membranes (membranes) and synaptic vesicular organelles (vesicular organelles) were probed by Western blot with the antibodies against the intracellular domain of NCAM140 and NCAM180, synaptophysin (synapt.), PSD95, and Na,K-ATPase. Arrows indicate NCAM isoforms detectable by the antibodies. Note that NCAM accumulates in the synaptic plasma membrane. Synaptic membranes, containing both presynaptic and postsynaptic portions, are also enriched in PSD95 and plasma membrane localized Na,K-ATPase. NCAM is also present in synaptic vesicular vesicles, which are highly enriched in synaptophysin but are free of PSD95 and Na,K-ATPase. NCAM180 detectable in the synaptic vesicular organelles is probably contained in postsynaptic transport organelles that are present in this fraction. NCAM immunoreactivity at $\sim 160 \mathrm{kDa}$ most likely is a proteolytic fragment of NCAM180. The graph shows quantitation of blots (mean $+\mathrm{SEM} ; n=3$ ) with the signal in contrast to AP1, which was not detectable in synaptic plasma membrane fractions of either genotype (data not shown), AP-3 was present in the synaptic plasma membrane fraction. Strikingly, the levels of AP-3 were sixfold higher in the plasma membrane fraction of NCAM- - compared to $N C A M+/+$ synaptosomes (Fig. $1 E)$. This raises the possibility that AP-3 may function at the plasma membrane or plasmalemmal invaginations in agreement with a previous report (Voglmaier et al., 2006) and that this function of AP-3 is increased under conditions of reduced recruitment of AP-2 and AP180 to the plasma membrane in NCAM-/- synaptic boutons.

NCAM accumulates on the presynaptic surface membrane

Since NCAM deficiency disturbs the subsynaptic distribution of adaptor proteins, we analyzed the distribution of NCAM itself. Synaptic boutons in cultured $N C A M+/+$ hippocampal neurons were visualized by labeling recycling synaptic vesicles with antibodies against the lumenal domain of synaptotagmin 1 applied to live neurons in media containing $47 \mathrm{~mm} \mathrm{~K}^{+}$ to induce synaptic vesicle exocytosis and endocytosis. Neurons were then fixed and colabeled with antibodies against NCAM, synaptophysin, and PSD95. The labeling showed that NCAM accumulations at the neuronal cell surface visualized with antibodies against the extracellular domain of

$\leftarrow$

homogenates set to $100 \%$. $^{*} p<0.05$, paired $t$ test. $D$, Synaptosomes and highly purified synaptic vesicles (synaptic vesicles) were probed by Western blot with polyclonal antibodies against a common epitope at the C terminus of NCAM140 and NCAM180, monoclonal antibody D3 against an NCAM180specific epitope in the intracellular domain of NCAM 180, and CSP. Arrows indicate NCAM isoforms detected by the antibodies. Note that NCAM140 is detectable in immunopurified synaptic vesicles. A smear above the NCAM140 band was reproducibly detectable in our preparations and may represent glycosylated NCAM140 or NCAM140-containing protein complexes, which were not fully dissociated by SDS-PAGE. Note that NCAM180 is not detectable in synaptic vesicles with NCAM180-specific antibodies even after prolonged exposure of the blot, while NCAM180 is readily detectable in synaptosomes. Mock immunopurification (mock) of synaptic vesicles with nonimmune lgs served as control of immunopurification. In these experiments, 4-12\% polyacrylamide gels were used to enable detection of both NCAM isoforms and CSP in one SDS-PAGE run, which was necessary to control for protein loading and specificity of synaptic vesicle immunopurification, resulting in NCAM140 and NCAM180 labeling patterns different from the data shown in C, in which $8 \%$ polyacrylamide gels were used and low molecular weight proteins were allowed to run out of the gel to achieve better separation of the NCAM bands. Scale bars: $10 \mu \mathrm{m}$. 
NCAM overlapped with synaptic boutons identified as overlapping clusters of synaptotagmin 1/synaptophysin immunoreactivity apposed to accumulations of PSD95 (Fig. 2A). In the CNS, NCAM180 expression is predominantly postsynaptic, both in brain tissue (Persohn et al., 1989; Schuster et al., 2001; Fux et al., 2003) and in cultured hippocampal neurons (Sytnyk et al., 2006). Presynaptic labeling thus reflects predominantly the distribution of the second major neuronal isoform of NCAM, NCAM140. The third major isoform of NCAM, glycosylphosphatidylinositol (GPI)linked NCAM120 is expressed in the CNS mainly by glia. To visualize the presynaptic localization of NCAM140 with sufficient spatial resolution (i.e., under conditions where postsynaptic NCAM is absent), we transfected cultured hippocampal neurons from NCAM-deficient $(N C A M-/-)$ mice with an NCAM140 expression plasmid. In synapses made by axons of transfected neurons on dendrites of nontransfected NCAM negative neurons, NCAM140 accumulations at the neuronal cell surface overlapped with synaptophysin clusters, which were apposed to PSD95 accumulations, consistent with a functional role for NCAM140 in synaptic vesicle recycling at excitatory synapses (Fig. 2B).

Western blot analysis of synaptosomes and synaptic plasma membranes isolated from adult wild-type $(N C A M+/+)$ mice showed that NCAM140 and NCAM180 are enriched in the synaptic plasma membrane fraction when compared to total brain homogenates (Fig. 2C). Low levels of NCAM immunoreactivity were detectable in the fraction containing synaptic vesicular organelles (Fig. $2 C$ ), i.e., the total pool of organelles released from synaptosomes by osmotic shock with both NCAM140 and NCAM180 being detectable in this fraction. This fraction was enriched in synaptophysin and negative for both Na,K-ATPase, an integral membrane protein localized exclusively to the surface membrane, and PSD95, a postsynaptic scaffold protein, highly enriched in the synaptic plasma membrane fraction (Fig. 2C). To analyze whether NCAM is present in synaptic vesicles, synaptic vesicles were first purified on a sucrose gradient and then further immunopurified using antibodies against CSP, a protein associated with synaptic vesicles via lipid anchors (Fig. 2D), to obtain highly pure synaptic vesicles. NCAM140 but not NCAM180 was detectable in highly pure synaptic vesicles (Fig. $2 D$ ) in accordance with previous reports (Takamori et al., 2006). The combined observations thus show that at the subsynaptic level, NCAM is predominantly present in the synaptic plasma membrane, thus being well poised to regulate recruitment of AP-2, AP180, and clathrin to this place.

\section{NCAM associates with AP-2 via a dileucine motif}

One possible explanation for the loss of clathrin/AP-2 from NCAM-/- synaptic plasma membranes might be a direct inter- action between NCAM and AP-2. To analyze whether NCAM indeed associates with AP-2 in synapses, NCAM was immunoprecipitated from synaptosomes. Western blot analysis of these immunoprecipitates showed that AP-2 but not AP-3 and AP-1 coimmunoprecipitated with NCAM (Fig. 3A). Approximately $3-5 \%$ of all AP-2 molecules present in synaptosomes were found in NCAM immunoprecipitates.

Analysis of the amino acid sequence of NCAM shows a potential AP-2 binding motif comprising a dileucine (LL) motif at position 741 of mouse NCAM140 and NCAM180 (at position 751 of rat NCAM140 and NCAM180; Fig. 3B). To confirm that the LL motif is important for NCAM/AP-2 complex formation in live cells, nonmutated rat NCAM140 or mutated rat NCAM140 with leucine 752 exchanged to alanine were transfected into $\mathrm{CHO}$ cells and assayed for their ability to associate with AP-2 by coimmunoprecipitation. Western blot analysis of NCAM immunoprecipitates showed that wild-type NCAM140 forms a complex with AP-2 (Fig. 3 C). Disruption of the LL motif by the LA mutation strongly reduced the levels of AP-2 coimmunoprecipitating with NCAM140 from transfected $\mathrm{CHO}$ cells to $21.1 \pm 7.1 \%(n=$ $4 ; p<0.01$, paired $t$ test) of the levels of AP2 coimmunoprecipitating with nonmutated NCAM140 set at 100\% (Fig. 3C), indi- 
A

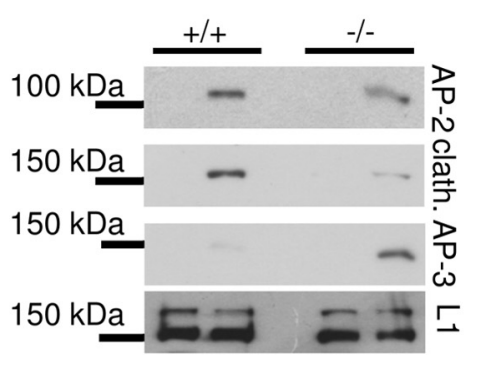

cytosol - + - +

\section{B}

competitor - 140ID LA140ID

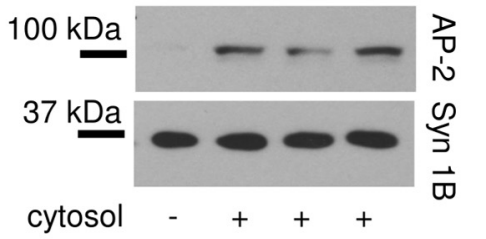
competitor

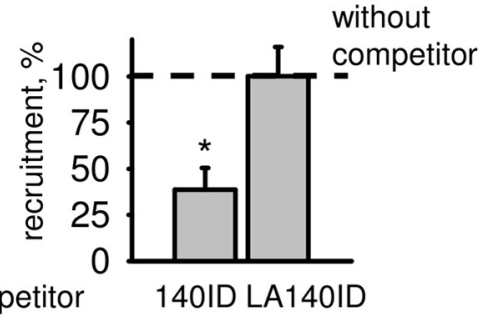

C competitor - BFA 140ID 140ID BH
BFA
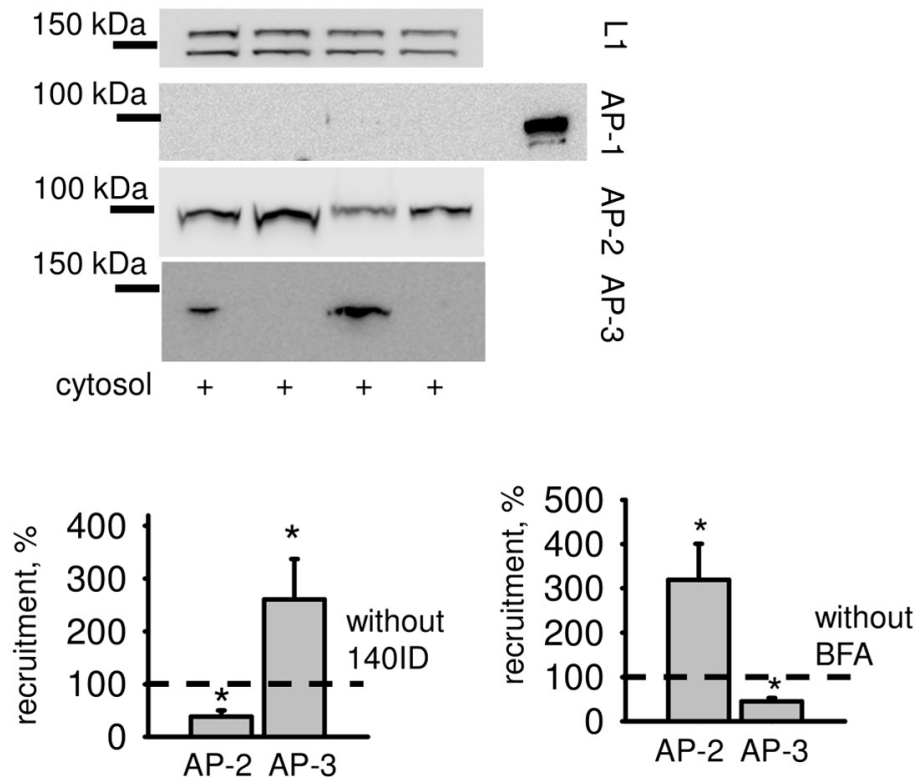

Figure 4. NCAM promotes binding of AP-2 versus AP-3 to synaptic plasma membranes. $A, N C A M+/+$ and NCAM $-/-$ synaptic plasma membranes were treated with alkali to strip peripheral proteins. The membranes were then incubated with cytosol and recruitment of AP-2, clathrin, and AP-3 from the cytosol to the membranes was assessed by Western blot. Note that alkali removed AP-2, clathrin, and AP-3 from the membranes, but not L1, which served as a loading control. Note more efficient recruitment of AP-2 and clathrin to NCAM + /+ synaptic membranes and enhanced recruitment of AP-3 to NCAM - / - synaptic membranes. The graph shows the quantitation of blots. Mean levels + SEM of AP-2, clathrin, and AP-3, recruited to NCAM - / synaptic membranes, are shown. The signals were normalized to NCAM+/+ levels (dashed line) set to $100 \%$. ${ }^{*} p<0.05$, paired $t$ test (compared to NCAM+/ $+; n=3$ ). B, C, Recruitment of AP-2 and AP-3 to NCAM+/+ synaptic membranes as analyzed by Western blot. When indicated, the cytosol was preincubated with BFA or competitors, either the nonmutated intracellular domain of NCAM140 (140ID) or 140ID with the mutated membrane-proximal dileucine motif (LA140ID). Note that 140ID but not LA140ID reduces recruitment of AP-2 to the membranes $(\boldsymbol{B})$. AP-3 recruitment is enhanced from the cytosol preincubated with 140 ID, while AP-2 recruitment is enhanced from the cytosol preincubated with BFA (C). Note that these effects are blocked when the cytosol was preincubated with 140ID and BFA (C). No recruitment of AP-1 is observed. Brain homogenate (BH) is included to show AP-1 bands at the expected molecular weight (C). Graphs show quantitation of blots. Mean levels + SEM of AP-2 and AP-3, recruited to synaptic membranes from cytosol in the presence of BFA or competitors, are shown. The signals were normalized to the signal without BFA or competitors (dashed lines) set to $100 \%$. $^{*} p<0.05$, paired $t$ test (compared to the signal without BFA or competitors; $n=3)$. L1 ( $\boldsymbol{A}, \boldsymbol{C})$ or syntaxin $1 \mathrm{~B}(\operatorname{syn} 1 \mathrm{~B} ; \boldsymbol{B})$ served as a loading control. cating that the LL motif indeed is required for efficient formation of the NCAM/ AP-2 complex in live cells.

NCAM promotes recruitment of AP-2 to the synaptic plasma membrane

To verify that NCAM induces attachment of AP-2 to the synaptic plasma membrane, we investigated the recruitment of AP-2 and clathrin from the synaptosomal cytosol of NCAM+/+ mice, which served as a source of these proteins, to synaptic membranes isolated from NCAM+/+ and $N C A M-/-$ mice. Before incubation with cytosol, synaptic membranes were exposed to high $\mathrm{pH}$ levels to strip peripheral proteins from the membranes (Fig. 4A; Haucke and De Camilli, 1999; Chernyshova et al., 2011). Western blot analysis of the synaptic membranes incubated with cytosol showed that cytosolic AP-2 and clathrin bound to $N C A M+/+$ and NCAM-/- synaptic membranes (Fig. $4 A)$. However, the efficiency of attachment of these proteins to NCAM-/membranes was approximately two to three times lower than to NCAM+/+ membranes (Fig. 4A), suggesting that NCAM regulates recruitment of AP- 2 and clathrin to synaptic membranes. Interestingly, recruitment of AP-3 from cytosol to NCAM-/- synaptic membranes was approximately three times higher than to $\mathrm{NCAM}+/+$ synaptic membranes (Fig. $4 A$ ), again suggesting that AP-3 substitutes for AP-2 in the absence of NCAM.

To analyze the role of the dileucine (LL) motif in recruitment of AP-2 to synaptic membranes, we investigated attachment of AP-2 to NCAM+/+ synaptic membranes from cytosol that was preincubated with nonmutated intracellular domain of NCAM140 (LL140ID) or with the intracellular domain of NCAM140 with the mutated membrane-proximal dileucine motif (LA140ID). Preincubation of cytosol with LL140ID inhibited binding of AP-2 to synaptic membranes (Fig. $4 B, C$ ), suggesting that recombinant 140ID competes with endogenous NCAM for AP-2. In contrast, LA140ID did not affect membrane association of AP-2 (Fig. 4B), indicating that the dileucine motif is an important determinant for NCAM-dependent recruitment of AP-2 to synaptic membranes.

Interestingly, when attachment of AP-2 to NCAM+/+ synaptic membranes was inhibited by pre-incubation with $140 \mathrm{ID}$, recruitment of AP-3 was enhanced (Fig. 4C), thus resembling in this aspect the NCAM-/- phenotype (Fig. 4A). These 
data suggest that AP-2 and AP-3 can substitute for each other, with NCAM favoring binding of AP-2 to synaptic membranes over that of AP-3. To investigate this idea further, we analyzed recruitment of AP-2 and AP-3 to NCAM+/+ synaptic membranes from cytosol preincubated with BFA. $\mathrm{AP}-3$ is recruited to membranes by the small G protein Arf1 (Ooi et al., 1998). Since BFA blocks nucleotide exchange on Arf1, it inhibits the ability of Arf1 to interact with membranes inducing the dispersion of Arfassociated AP complexes such as AP-3 to the cytosol (Robineau et al., 2000). BFAinduced inhibition of AP-3 recruitment to NCAM+/+ synaptic membranes was accompanied by increased attachment of AP-2 (Fig. 4C), further suggesting that AP-2 and AP-3 can substitute for each other. The effects of 140ID and BFA were negated with respect to AP-2 recruitment when they were coapplied together (Fig. 4C). AP-1 was not recruited to synaptic membranes either in the presence or absence of 140ID or BFA (Fig. 4C).

\section{NCAM deficiency impairs age-} dependent substitution of AP-3 with AP-2 at synaptic membranes

BFA-sensitive synaptic vesicle recycling has been suggested to represent an immature mode of synaptic vesicle recycling in isolated motoneuron axons (Zakharenko et al., 1999). To investigate whether AP-3 function diminishes with age also in CNS synapses, levels of AP-3 were analyzed in synaptosomes and synaptic membranes isolated from brains of postnatal day 7 (P7) and P60 NCAM+/+ mice. Western blot analysis showed that not only the total levels of AP-3 in synaptosomes, but also the fraction of AP-3 attached to synaptosomal plasma membranes [characterized by the ratio $I_{\mathrm{AP}-3}=$ (levels of AP-3 in synaptic plasma membranes)/(levels of AP-3 in synaptosomes)] was strongly reduced in synaptosomes from P60 versus P7 mice (Fig. 5A). In contrast, $I_{\mathrm{AP}-2}$ and $I_{\mathrm{AP} 180}$ were strongly increased in $\mathrm{P} 60$ versus P7 NCAM+/+ mice (Fig. $5 A$ ), sug-

gesting that the mechanism of synaptic vesicle membrane retrieval had switched from AP-3- to AP-2-dependent mechanisms. The total levels of AP-3 and AP-2 in synaptosomes and synaptic plasma membranes from P7 NCAM-/- and P7 $N C A M+/+$ mice were similar (Fig. $5 A$ ). In contrast to $N C A M+/+$ mice, NCAM-/- mice displayed increased $I_{\text {AP-3 }}$ in $\mathrm{P} 60$ versus $\mathrm{P} 7$. While $I_{\mathrm{AP}-2}$ also slightly increased with age in NCAM-/- mice, this increase was much lower than in $N C A M+/+$ mice (Fig. $5 A$ ). Thus, our data suggest that NCAM deficiency impairs the developmental switch from AP-3- to AP-2-dependent modes of synaptic vesicle recycling, perhaps by inhibiting NCAM- and age-dependent recruitment of AP-2 coimmunoprecipitate with NCAM.
A synaptic plasma membranes
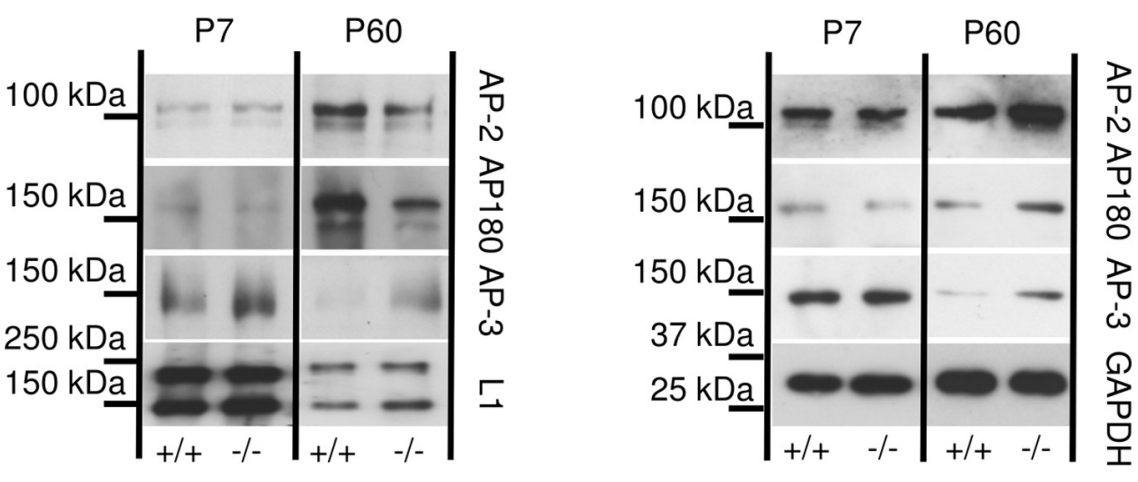
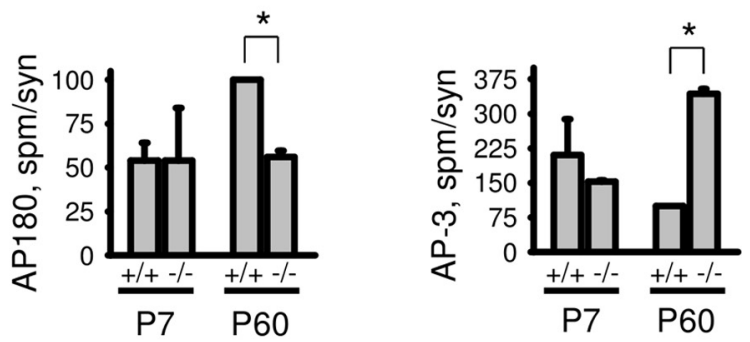

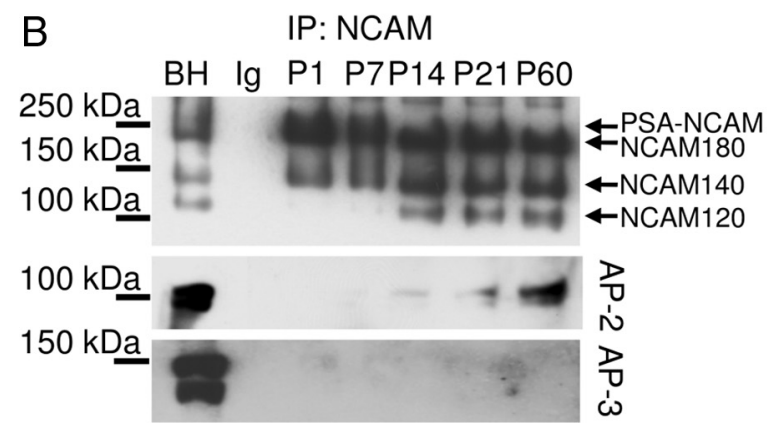

Figure 5. NCAM promotes substitution of AP-3 by AP-2 in synaptic plasma membranes during postnatal development. $A$, Levels of AP-2, AP-3, and AP180 in NCAM +/+ and NCAM - / - synaptic plasma membranes and synaptosomes from P7 or P60 synaptic plasma membranes. Graphs show quantitation of blots. Mean ratios + SEM of protein levels in synaptic plasma mem${ }^{*} p<0.05$, paired $t$ test $(n=3)$. Labeling for L1 (for synaptic membranes) or GAPDH (for synaptosomes) served as a loading control. B, NCAM immunoprecipitates (IP) from brain lysates of P1, P7, P14, P21, and P60 NCAM +/+ mice were probed with were applied for comparison. Mock IP with nonimmune rabbit lgs was performed for control. A broad band of NCAM immunoreactivity observed at $200 \mathrm{kDa}$ in brains of P1-P7 mice represents polysialylated NCAM (PSA-NCAM). Note that levels of nonpolysialylated NCAM140 and efficiency of the coimmunoprecipitation of AP-2 with NCAM increase with age. AP-3 does not

to synaptic plasma membranes. In accordance with this idea, the amount of AP-2, which coimmunoprecipitated with NCAM from $N C A M+/+$ brain lysates, increased strongly with age reaching its peak in P60 mice (Fig. 5B). This increase in complex formation correlated with an increase in the levels of nonpolysialylated NCAM140 (Fig. 5B), which accumulates in synapses (Fig. 3A).

\section{Levels of AP-2/AP180 containing synaptic vesicles are} reduced in NCAM-/- synapses

Reduced recruitment of AP-2, AP180, and clathrin to NCAM-/- synaptic membranes may impair formation of synaptic vesicles via an AP-2-dependent pathway. In agreement, levels of AP-2, AP180, and clathrin were reduced in synaptic 
A
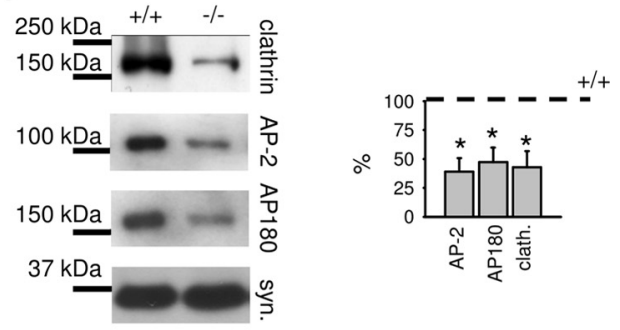

B
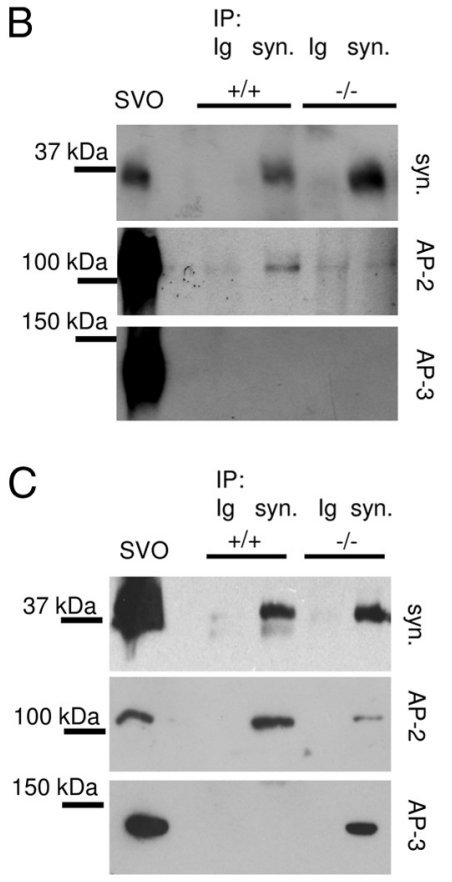

Figure 6. The amount of AP-2/AP180/clathrin-coated vesicles is reduced in NCAM-/versus $N C A M+/+$ mice. $A$, Synaptic vesicles purified in a sucrose gradient were probed by Western blot with the antibodies against clathrin, AP-2, AP180, and synaptophysin (syn.). Note lower levels of clathrin, AP-2, and AP180 and unchanged levels of synaptophysin in NCAM - /versus NCAM+/+ synaptic vesicles. The graph shows quantitation of the blots (mean + SEM; $n=3$ ) with the signal in NCAM+/+ mice set to $100 \% .{ }^{*} p<0.05$, paired $t$ test. $\boldsymbol{B}$, Synaptic vesicles purified in a sucrose gradient were further purified by immunoprecipitation (IP) with antibodies against synaptophysin and probed by Western blot for synaptophysin, AP-2, and AP-3. Mock immunoprecipitation with nonimmune rabbit lgs was performed for control. Note unchanged levels of synaptophysin and reduced levels of AP- 2 in NCAM - / - synaptic vesicles. Synaptic vesicles are negative for AP-3. C, Synaptophysin positive organelles were immunoprecipitated with antibodies against synaptophysin from the crude synaptic vesicular organelle (SV0) fraction and probed by Western blot for synaptophysin, AP-2, and AP-3. Note unchanged levels of synaptophysin, reduced levels of AP-2, and increased levels of AP-3 in NCAM-/organelles. $\boldsymbol{B}, \boldsymbol{C}$, The crude synaptic vesicular organelle fraction was applied to the gel for comparison.

vesicular organelles from NCAM-/- synaptosomes as compared to NCAM+/+ synaptosomes (Fig. 1E). Since these organelles contain various membranous structures including endosomes and synaptic vesicles, we further fractionated this crude vesicle fraction from lysed NCAM+/+ and NCAM-/synaptosomes on a sucrose gradient to isolate synaptic vesicles (Huttner et al., 1983; Thoidis et al., 1998; Leshchyns'ka et al., 2006; Andreyeva et al., 2010). These purified NCAM+/+ and NCAM - / - synaptic vesicles contained similar levels of synaptophysin indicating that the number of synaptic vesicles was identical in synapses of both genotypes (Figs. 6A, 7B). However, the levels of AP-2, AP180 and clathrin were decreased in NCAM-/synaptic vesicles (Fig. 6A). A similar result was observed for syn- aptic vesicles that were further purified from the synaptic vesicle fraction by immunoisolation with antibodies against synaptophysin: AP-2 levels in these highly pure NCAM-/- synaptic vesicles were reduced to $18.9 \pm 2.7 \%(n=6 ; p<0.0001$, paired $t$ test) of AP-2 levels in NCAM+/+ synaptic vesicles set at $100 \%$ (Fig. 6B). AP-3 has been found on endosomes and implicated in the formation of synaptic vesicles from endosomes (Salem et al., 1998; Blumstein et al., 2001). In agreement, AP-3 was present in the total pool of synaptophysin-positive organelles immunoisolated with antibodies against synaptophysin from the crude fraction of vesicular organelles (Fig. $6 \mathrm{C}$ ), but not in highly purified synaptic vesicles (Fig. 6B). The levels of AP-3 in synaptophysinpositive organelles from NCAM-/- synaptosomes were strongly increased to $496.6 \pm 123.7 \%(n=4 ; p<0.05$, paired $t$ test $)$ of AP-3 levels in NCAM+/+ organelles set at $100 \%$, while levels of AP- 2 in synaptophysin-positive organelles from NCAM-/- synaptosomes were reduced to $19.83 \pm 1.8 \%(n=4 ; p<0.001$, paired $t$ test $)$ of AP-2 levels in NCAM+/+ organelles set at 100\% (Fig. 6C). These observations further suggest that reduced targeting of AP-2, AP180, and clathrin to synaptic membranes in NCAM-/- synapses impairs AP-2/AP180-mediated formation of clathrin-coated synaptic vesicles.

NCAM deficiency results in upregulation of AP-3-dependent bulk retrieval from the presynaptic membrane

In contrast to AP-2, AP-3-mediated vesicle formation does not require clathrin (Newman et al., 1995; Shi et al., 1998) and is involved in the regeneration of synaptic vesicles from bulk endosomes (Cheung and Cousin, 2012). Organelles resulting from bulk membrane retrieval can be selectively labeled with large $>40$ $\mathrm{kDa}$ fluid-phase markers (Holt et al., 2003) that have limited access to small synaptic vesicles budding from the surface membrane (Berthiaume et al., 1995; Araki et al., 1996). We have used this feature to compare the activity-dependent bulk membrane retrieval in NCAM+/+ and NCAM-/- synaptic boutons by analyzing the uptake of $\sim 44 \mathrm{kDa}$ HRP from the culture medium to synaptic boutons.

Cultured hippocampal neurons were stimulated for $90 \mathrm{~s}$ with $47 \mathrm{mM} \mathrm{K}^{+}$in the presence of HRP, a protocol that results in the massive exocytosis of the entire pool of recycling synaptic vesicles followed by membrane retrieval via clathrin-mediated endocytosis and bulk endosomes (Leshchyns'ka et al., 2006; Cheung et al., 2010; Cheung and Cousin, 2012). Neurons were then fixed and subjected to analysis by electron microscopy, which showed that HRP accumulated in vesicles close in size and shape to bona fide synaptic vesicles and in larger endosome-like structures of irregular shapes (Fig. 7A). The numbers of HRP-containing synaptic vesicles and endosomes were analyzed in sections of synaptic boutons imaged randomly and in a blinded manner with respect to genotype and treatment. This analysis showed that the mean number of HRP-containing structures was strongly increased in $N C A M-/-$ synaptic boutons compared to $N C A M+/+$ neurons (Fig. $7 A, B$ ), indicating that bulk membrane endocytosis is elevated in NCAM-/- synapses.

Given the increased recruitment of AP-3 together with our failure to detect AP-1 recruitment to synaptic membranes from NCAM-/- neurons (compare Fig. 4C), we hypothesized that elevated bulk membrane endocytosis might be mediated by AP-3 . To investigate the role of AP-3 in HRP uptake, neurons were preincubated with BFA for $2 \mathrm{~h}$ before analysis of HRP uptake in response to $47 \mathrm{mM} \mathrm{K}^{+}$. BFA strongly reduced HRP uptake into $N C A M-/-$ synaptic boutons (Fig. $7 A, B$ ), consistent with the idea that AP-3 is involved in bulk membrane retrieval in 
NCAM-/- synapses. However, this effect was incomplete, suggesting that BFA-dependent AP-3-mediated bulk membrane retrieval coexists with a BFAindependent pathway. Somewhat surprisingly, BFA did not inhibit, but rather increased HRP uptake into NCAM+/+ synaptic boutons (Fig. $7 A, B$ ). Accumulation of HRP in NCAM+/+ terminals following BFA application might be related to the inhibition of organelle processing within the synaptic bouton, a process that likely depends on AP-3 (Fig. 7D) and possibly AP-1 [consistent with previous data by Cheung and Cousin (2012)]. In agreement, HRP containing organelles were larger in BFA treated NCAM+/+ synaptic boutons compared to mock-treated controls. This phenotype presumably reflects impaired budding of vesicles from synaptic vesicle protein containing endosomes in the presence of BFA (Fig. 7C). More importantly, this observation suggests that AP-2and AP-3-mediated pathways intersect in $N C A M+/+$ synaptic boutons at the level of endosomal intermediates (Fig. 7D).

The number of small synaptic vesicles (diameter of $\leq 40 \mathrm{~nm}$ ) per synapse section area was on average slightly lower in BFA treated compared to untreated control $N C A M+/+$ neurons (Fig. $7 A, B$ ). This reduction could be due to reduced AP-3dependent reformation of synaptic vesicles from endosomal organelles as suggested previously (Voglmaier et al., 2006), and/or overall reduced biogenesis of synaptic vesicles from the trans-Golgi network (Hannah et al., 1999) over the time of drug application. Interestingly, the effect of BFA on synaptic vesicle number was reduced in NCAM-/- synaptic boutons (Fig. $7 A, B)$. This may reflect BFA-induced substitution of the AP-3-dependent pathway of synaptic vesicle recycling by an AP-2/ AP180-dependent route as suggested by our biochemical data (Figs. $4 C, 8 C$ ) or the presence of AP-2/AP180- and AP-3independent recycling pathways operating in NCAM-/- synaptic boutons.

NCAM-/- synapses combine AP-2and AP-3-dependent pathways of synaptic vesicle endocytosis

Next, we compared the overall efficiency of synaptic vesicle endocytosis by using the lipophilic dye FM1-43, which labels the total recycling pool of vesicles including those generated by bulk membrane retrieval; the latter is thought to represent a minor fraction of the total recycling vesicle pool (Teng and Wilkinson, 2000). A fixable analog of FM1-43 was used in these experiments, and the levels of FM1-43 dye were measured in synaptic boutons visualized with antibodies to blocked by BFA are indicated.
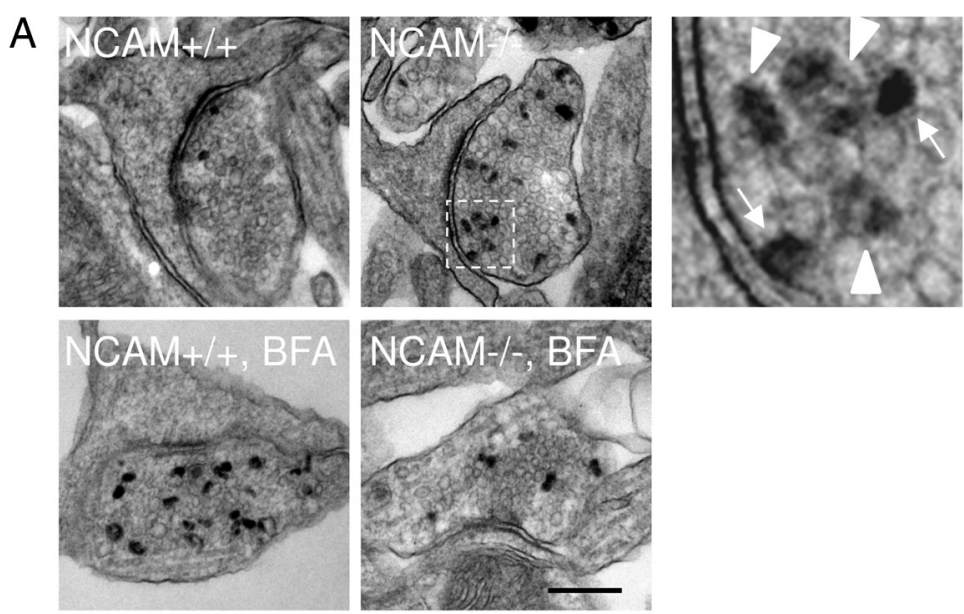

\section{B}
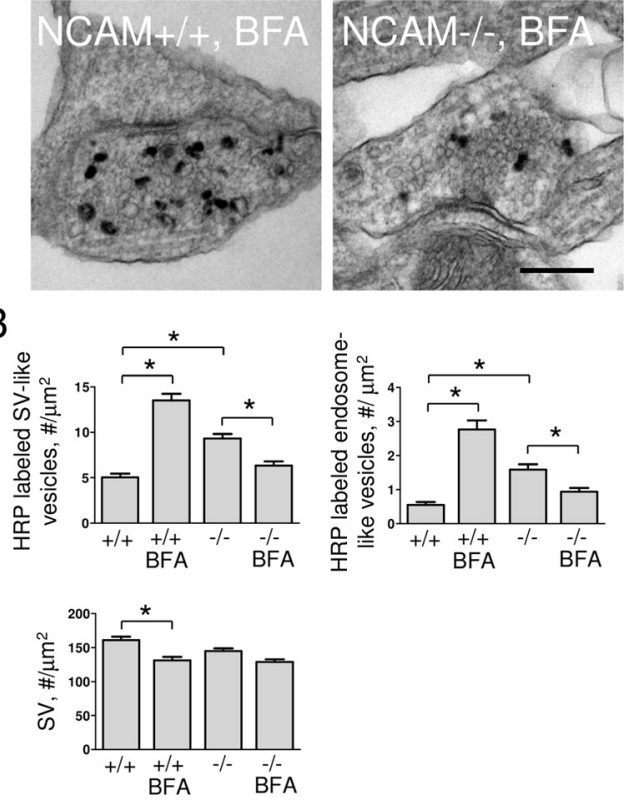

C
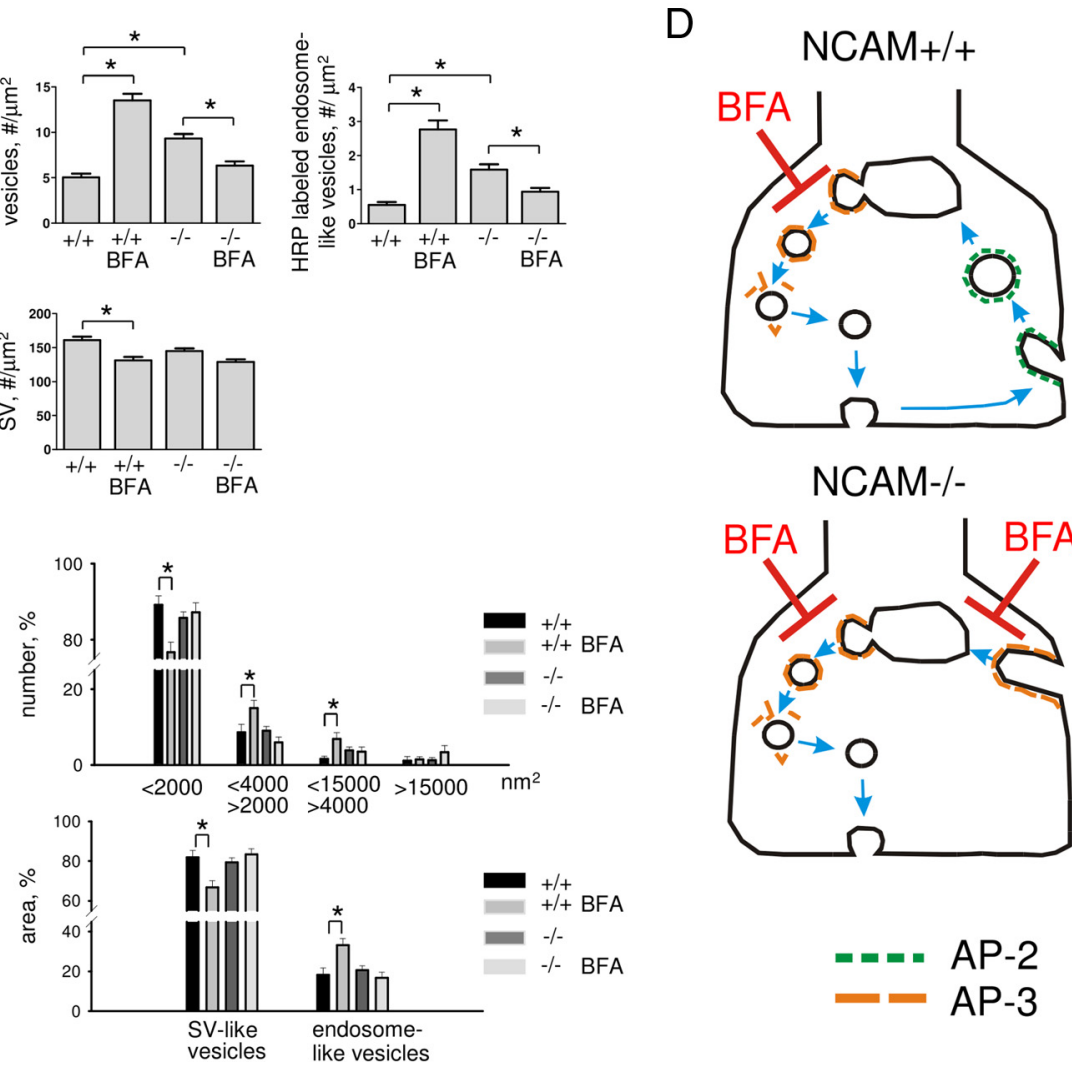

NCAM-/-
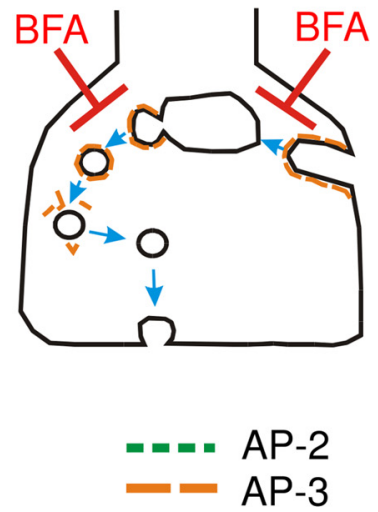

Figure 7. AP-3-mediated bulk membrane retrieval is enhanced in NCAM-/- synaptic boutons. $A, N C A M+/+$ and NCAM $-/-$ cultured hippocampal neurons were allowed to take up HRP in the presence of $47 \mathrm{~mm} \mathrm{~K}{ }^{+}$applied for $90 \mathrm{~s}$. Where indicated, neurons were pretreated with BFA for $1 \mathrm{~h}$. Representative electron micrographs of synapses are shown. HRP-loaded vesicles are seen as dark core structures. Scale bar, $300 \mathrm{~nm}$. HRP uptake is enhanced in NCAM - / - synaptic boutons when compared to NCAM+/+ synaptic boutons. The number of HRP positive organelles is increased in NCAM+/+ synaptic boutons and reduced in NCAM-/- boutons after BFA application. Higher magnification of the area outlined in NCAM - / - synapse (right) shows that HRP was taken up by synaptic vesicle-like structures (arrows) and larger endosome-like structures (arrowheads). B, Graphs show numbers of SV-like structures with the cross-section area $<2000 \mathrm{~nm}^{2}$, endosome-like structures with the cross-section area $>2000 \mathrm{~nm}^{2}$, and the total number of SVs including HRP-loaded and nonlabeled SV s counted per synapse section area. C, Graphs show numbers of HRP-loaded vesicles of the indicated size normalized to the total number of HRP-loaded vesicles per synaptic bouton section (top) and the total cross-section area of all SV-like structures or endosome-like structures normalized to the total cross-section area of all HRP loaded organelles per synaptic bouton section (bottom). In $\boldsymbol{B}$ and $\boldsymbol{C}$, mean values + SEMareshown. ${ }^{*} p<0.05, t$ test $(n>100$ synapses were analyzed from $4-6$ coverslips). $\boldsymbol{D}$, Ascheme showing the hypothetical role of AP-2 and AP-3 in bulk membrane retrieval in NCAM+/+ and NCAM - / - synaptic terminals. AP-3-dependent steps

the synaptic vesicle marker SV2 after fixation. FM1-43 uptake in response to $90 \mathrm{~s}$ stimulation with $47 \mathrm{mM} \mathrm{K}^{+}$was reduced by $\sim 20 \%$ in synaptic boutons from $N C A M-/-$ neurons when compared to $N C A M+/+$ neurons (Fig. $8 A$ ). This reduction 
A
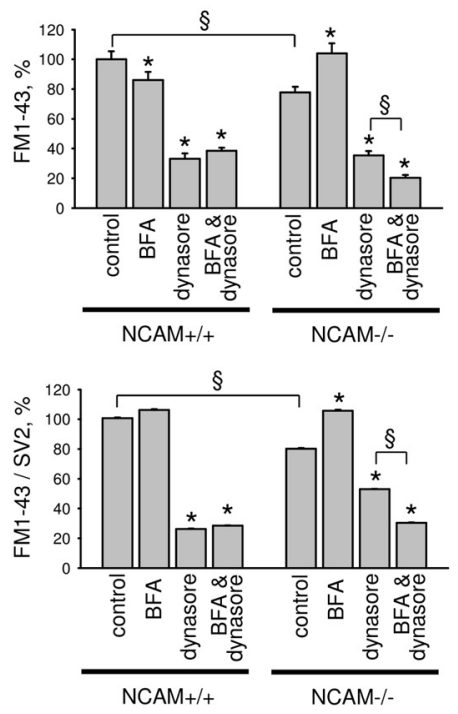

B
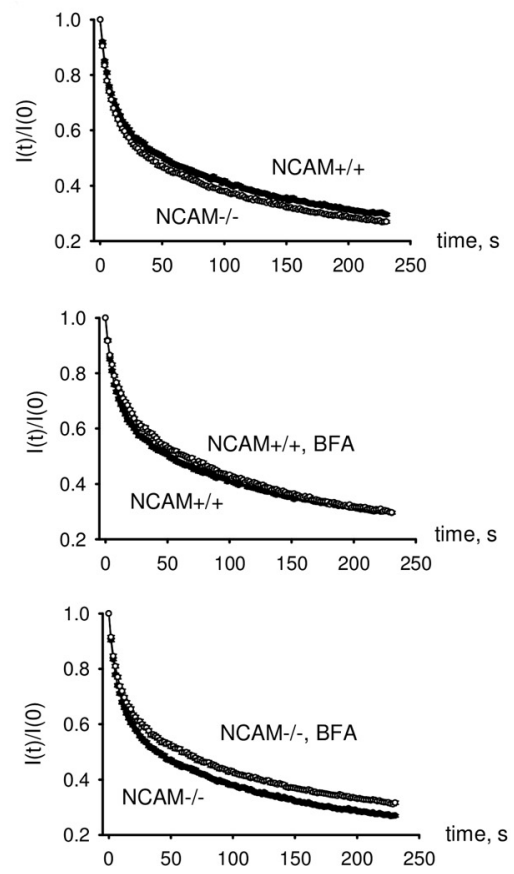

Figure 8. AP-3-dependent synaptic vesicle endocytosis and intrasynaptic processing are upregulated in NCAM-/- synaptic boutons. $A$, Presynaptic boutons of NCAM+/+ and NCAM - / - cultured hippocampal neurons that were either not treated (control) or treated as indicated with BFA and dynasore were loaded with the fixable analog of FM1-43 applied in the presence of $47 \mathrm{~mm} \mathrm{~K}^{+}$for $90 \mathrm{~s}$. After washing, neurons were fixed and colabeled with antibodies against the presynaptic marker protein SV2 to visualize presynaptic boutons. Graphs show quantification (mean + SEM) of FM1-43 fluorescence levels in SV2 accumulations (top) or the ratio of FM1-43 fluorescence levels to SV2 immunofluorescence levels (bottom). Values were normalized to the levels in control NCAM+/+ neurons set to 100\%. Compared to NCAM+/+ neurons, FM1-43 uptake in NCAM-/- presynaptic boutons is reduced and increased in response to BFA. Note that BFA and dynasore have an additive effect on FM1- 43 uptake in $N C A M-/$ - but not NCAM+/+ presynaptic boutons. ${ }^{*} p<0.05$ ( $t$ test compared to control neurons of the same genotype); ${ }^{\S} p<0.05$ ( $t$ test compared as indicated); $n>20$ images of neurons with $N>200$ synapses per image were analyzed. $B, G$ Gaphs show quantification (mean + SEM) of FM1-43 release from presynaptic boutons of NCAM $+/+$ and NCAM $-/-$ cultured hippocampal neurons in response to $47 \mathrm{~mm} \mathrm{~K}^{+}$. Values $[/(\mathrm{t})]$ were normalized to FM1- 43 levels before stimulation $[/(0)]$. Where indicated, neurons were preincubated with BFA. BFA inhibits FM1-43 release from the presynaptic boutons of NCAM-/neurons. C, A diagram showing the roles of AP-2 and AP-3 adaptor proteins in synaptic vesicle endocytosis and intrasynaptic processing in NCAM+/+ and NCAM-/- synaptic terminals. AP-3- and AP-2-dependent steps blocked by BFA and dynasore, respectively, are indicated.

was not due to reduced exocytosis of synaptic vesicles, since the release of FM1-43 from synaptic boutons in response to 47 $\mathrm{mM} \mathrm{K}^{+}$, indicative of synaptic vesicle exocytosis, was similar in $N C A M-/-$ synaptic boutons compared to $\mathrm{NCAM}+/+$ neurons (Fig. 8B). Impaired uptake of FM1-43 in NCAM-/- synaptic boutons was also not caused by reduced total numbers of synaptic vesicles, which were similar in NCAM+/+ and NCAM-/synapses (Fig. 7). Hence, we conclude that synaptic vesicle endocytosis is impaired in NCAM-/- synaptic boutons.

When neurons were preincubated with BFA for $2 \mathrm{~h}$, the uptake of FM1-43 into synaptic boutons from $N C A M+/+$ neurons in response to $90 \mathrm{~s}$ stimulation with $47 \mathrm{mM} \mathrm{K}^{+}$ slightly decreased (Fig. $8 A$ ), probably due to a small reduction in the number of synaptic vesicles. In agreement, there was no difference in FM1-43 uptake between untreated and BFA treated NCAM+/+ neurons when FM1-43 levels were normalized to the levels of the synaptic vesicle marker protein SV2 (Fig. 8A). In contrast to the observations on NCAM-/- NMJs, treatment of NCAM-/- hippocampal neurons with BFA surprisingly increased the level of FM1-43 internalization into synaptic boutons (Fig. 8A). This increase could be due to slower processing of synaptic vesicles in BFA-treated NCAM-/synaptic terminals resulting in dye trapping. In agreement with this possibility, FM143 release in response to $47 \mathrm{mM} \mathrm{K}^{+}$was slower and incomplete in synaptic boutons from BFA treated versus untreated NCAM $-/-$ neurons (Fig. $8 B$ ). BFA had no effect on FM1-43 release in NCAM+/+ synaptic boutons (Fig. 8B).

Our biochemical data indicate that application of BFA results in the substitution of AP-3 with AP-2 at the plasma membrane (Fig. 4C), causing a switch from AP-3- to AP-2-dependent modes of synaptic vesicle recycling (Fig. $8 C$ ). Hence, it is difficult to judge the role of AP-3 in synaptic vesicle endocytosis using data obtained with BFA. To compare the role of AP-3 in synaptic vesicle endocytosis in $N C A M+/+$ and NCAM-/- neurons, cells were treated for $2 \mathrm{~h}$ with dynasore, a small molecule inhibitor of the large GTPase dynamin. Such treatment blocks clathrin/AP-2- and dynamin-dependent synaptic vesicle endocytosis (Newton et al., 2006), while leaving AP-3-dependent routes unperturbed. Dynasore inhibited FM1-43 uptake into NCAM+/+ synaptic boutons by $\sim 80 \%$ (Fig. $8 A$ ), in agreement with previous reports (Newton et al., 2006). In contrast, in NCAM-/neurons dynasore inhibited FM1-43 uptake by only $\sim 50 \%$ (Fig. $8 A$ ), consistent with the upregulation of dynamin-independent AP-3dependent routes of synaptic vesicle endocytosis in NCAM-/neurons. In agreement with this interpretation, coapplication of dynasore with BFA inhibited FM1-43 uptake in NCAM-/- 
synaptic boutons to a level similar to that seen in BFA plus dynasore-treated NCAM $+/+$ neurons.

Together, our data indicate that in contrast to NCAM+/+ synapses that predominantly use an AP-2/AP180/dynamindependent pathway for synaptic vesicle endocytosis, NCAM-/- synapses combine AP-2- and AP-3-dependent routes for synaptic vesicle reformation.

NCAM deficiency results in impaired synaptic vesicle endocytosis in hippocampal neurons

To analyze synaptic vesicle endocytosis with higher temporal resolution, we visualized synaptic vesicle recycling in live NCAM+/+ and NCAM-/- cultured hippocampal neurons by transfecting them with a $\mathrm{pH}$-sensitive form of green fluorescent protein (GFP) fused to the lumenal domain of synaptobrevin 2, also called VAMP2 (VAMP2-pHluorin). This provides a sensitive optical probe to follow exocytosis and endocytosis of synaptic vesicles in real time (Miesenbock et al., 1998). Stimulation with 47 $\mathrm{mM} \mathrm{K}^{+}$for $90 \mathrm{~s}$ resulted in an increase in VAMP2-pHluorin fluorescence at synaptic boutons due to synaptic vesicle exocytosis and exposure of the lumenal pHluorin tag to the neutral extracellular space (Fig. 9A). Following stimulation, the buffer was exchanged to low ( $4 \mathrm{~mm}$ ) $\mathrm{K}^{+}$containing buffer resulting in a reduction in VAMP2-pHluorin fluorescence intensity due to endocytosis and vesicle reacidification (Fig. 9B). As seen in Figure 9, $B$ and $E$, the efficiency of VAMP2-pHluorin endocytosis characterized by the difference between pHluorin fluorescence levels reached during stimulation and after recovery $\left(I_{\mathrm{r}}\right)$ was significantly reduced in $N C A M-/-$ neurons when compared to $\mathrm{NCAM}+/+$ littermate neurons. The speed of VAMP2-pHluorin endocytosis characterized by $t_{1 / 2}$ tended to be slower in NCAM-/- versus $N C A M+/+$ neurons (not statistically significant).

Quenching of pHluorin fluorescence depends on the rate of synaptic vesicle endocytosis and acidification of the synaptic vesicle lumen. The levels of the largest $(116 \mathrm{kDa})$ subunit of the proton ATPase, which is essential for proton pump activity and synaptic vesicle acidification, were similar in synaptic vesicles isolated from $\mathrm{NCAM}+/+$ and NCAM-/- mice (Fig. 9C). This observation renders it unlikely that reduced quenching of VAMP2-pHluorin fluorescence in NCAM-/- synaptic boutons is due to reduced levels of the vATPase. Hence, the defect in VAMP2-pHluorin quenching most likely results from its impaired endocytosis in NCAM-/- synaptic boutons.

A

B

E
VAMP2-pHluorin
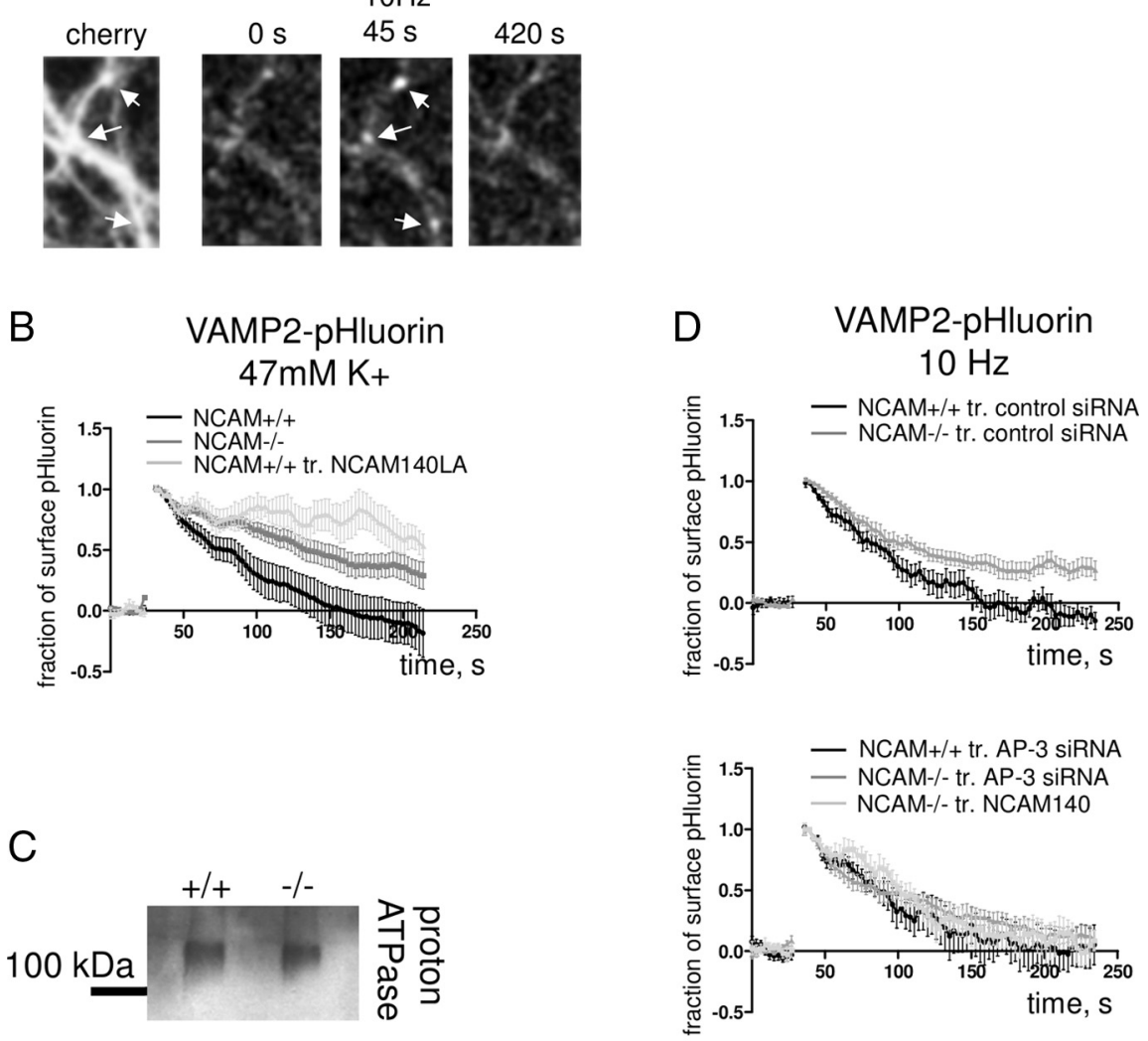

\begin{tabular}{|c|c|c|c|c|}
\hline stimulation & genotype & co-transfection & $\mathrm{I}_{\mathrm{r}}, \%$ & $\mathrm{t}_{1 / 2}, \mathrm{~s}$ \\
\hline \multirow{3}{*}{$47 \mathrm{mM} \mathrm{K}+$} & NCAM+/+ & pCDNA3 & $83.3 \pm 4.1$ & $51.1 \pm 6.7$ \\
\cline { 2 - 5 } & NCAM-/- & pCDNA3 & $\mathbf{6 4 . 1} \pm \mathbf{6 . 1} *$ & $58.6 \pm 7.0$ \\
\cline { 2 - 5 } & NCAM+/+ & NCAM140LA & $\mathbf{4 6 . 2} \pm \mathbf{1 4 . 1} *$ & $32.3 \pm 10.4$ \\
\hline \multirow{4}{*}{$10 \mathrm{~Hz}$} & NCAM+/+ & control siRNA & $95.0 \pm 2.2$ & $38.8 \pm 5.9$ \\
\cline { 2 - 5 } & NCAM-/- & control siRNA & $\mathbf{7 4 . 5} \pm \mathbf{6 . 5} *$ & $47.7 \pm 4.6$ \\
\cline { 2 - 5 } & NCAM+/+ & AP-3 siRNA & $80.0 \pm 6.1$ & $34.9 \pm 5.2$ \\
\cline { 2 - 5 } & NCAM-/- & AP-3 siRNA & $86.9 \pm 4.5$ & $38.7 \pm 4.7$ \\
\cline { 2 - 5 } & NCAM-/- & NCAM140 & $92.5 \pm 4.1$ & $54.7 \pm 12.4$ \\
\hline
\end{tabular}

Figure 9. Endocytosis of VAMP2-pHluorin is reduced in NCAM - / - synaptic boutons. $A, N C A M+/+$ neurons were cotransfected with cherry and VAMP2-pHluorin. Neurons were stimulated with $1 \mathrm{~ms}$ bipolar current pulses at $10 \mathrm{~Hz}$ to yield fields of 10 $\mathrm{V} / \mathrm{cm}$. Gray scale images show pHluorin fluorescence in neurons before $(0 \mathrm{~s})$, during $(45 \mathrm{~s})$, and after $(420 \mathrm{~s})$ stimulation. Note an increase in pHluorin fluorescence intensity in synaptic boutons in response stimulation (arrows). $\boldsymbol{B}$, VAMP2-pHluorin endocytosis monitored in synaptic boutons of NCAM $+/+$ and NCAM - / - cultured hippocampal neurons cotransfected (tr.) with an empty pCDNA3 vector, or NCAM+/+ neurons cotransfected with NCAM140LA in the pCDNA3 vector. Neurons were stimulated with 47 $\mathrm{mm} \mathrm{K}^{+}$and allowed to recover in $4 \mathrm{~mm} \mathrm{~K}^{+}$. C, Synaptic vesicles purified from NCAM+/+ and NCAM $-/-$brains were probed by Western blot with antibodies against the largest subunit $(116 \mathrm{kDa})$ of proton ATPase. Note that the levels of proton ATPase are not changed in NCAM - / - versus NCAM + / + synaptic vesicles. D, VAMP2-pHluorin endocytosis monitored in synaptic boutons of cultured NCAM+/+ and NCAM - / - hippocampal neurons cotransfected with control or AP-3 siRNA or NCAM140. Neurons were stimulated with $1 \mathrm{~ms}$ bipolar current pulses at $10 \mathrm{~Hz}$ to yield fields of $10 \mathrm{~V} / \mathrm{cm}$. In $\boldsymbol{B}$ and $\boldsymbol{D}$, fluorescence intensity levels before stimulation were set to 0 , and signals during the recovery time were normalized to the peak intensity reached during stimulation. Mean values \pm SEM are shown ( $n=14-25$ synapses from $8-10$ coverslips were recorded in each group). $\boldsymbol{E}$, Mean \pm SEM. values for pHluorin fluorescence recovery efficiency $\left(I_{\mathrm{r}}=\left(1-I_{\text {end }}\right) * 100 \%\right)$ and for time constants $\left(t_{1 / 2}\right)$ are shown. ${ }^{*} p<0.05$, one-way ANOVA with Dunnett's multiple comparison post-test.

To analyze whether VAMP2 retrieval is also sensitive to the disruption of the NCAM/AP-2 complex in wild-type neurons, we also analyzed VAMP2 retrieval after $90 \mathrm{~s}$ stimulation with $47 \mathrm{mM}$ $\mathrm{K}^{+}$in NCAM+/+ neurons transfected with NCAM140LA. Since the NCAM140LA mutant contains a wild-type extracellular do- 
main, it is able to compete with endogenous wild-type NCAM for homophilic and heterophilic interactions in the synaptic membrane, which target NCAM to synapses (Leshchyns'ka et al., 2011), and may thus function as a dominant-negative construct by substituting endogenous NCAM at synapses. In agreement, NCAM140LA was detectable in synaptic boutons of transfected neurons by immunofluorescence labeling (data not shown). Endocytosis of VAMP2-pHluorin was strongly inhibited in NCAM140LA expressing NCAM+/+ neurons (Fig. 9B).

To analyze whether NCAM deficiency also affects synaptic vesicle endocytosis after a milder stimulation protocol, VAMP2 retrieval was analyzed after subjecting neurons to stimulation with 900 action potentials applied at $10 \mathrm{~Hz}$, a protocol that does not activate bulk endocytosis. Also with this stimulation protocol, VAMP2-pHluorin endocytosis was reduced in NCAM-/neurons versus $N C A M+/+$ neurons (Fig. $9 D, E$ ).

Since removal of AP-3 from the plasma membrane promotes recruitment of AP-2 (Fig. 4C), we also compared VAMP2 retrieval after $10 \mathrm{~Hz}$ stimulation in NCAM+/+ and NCAM-/neurons transfected with AP-3 siRNA. The difference between genotypes was eliminated in neurons transfected with AP-3 siRNA (Fig. 9D,E). This effect might be due to reactivation of the AP-2 pathway after inactivation of AP-3 in NCAM-/- neurons or could reflect other AP-independent mechanisms of bulk membrane retrieval.

A crucial role for NCAM140 in regulating VAMP2 endocytosis was further confirmed by the observation that overexpression of wild-type NCAM140 in NCAM-/- neurons increased VAMP2-pHluorin endocytosis (Fig. 9D,E). These data thus indicate that NCAM140 regulates endocytic retrieval of VAMP2 from the neuronal surface, presumably by facilitating recruitment of AP-2/AP180 to the presynaptic plasma membrane (compare with Fig. 1).

\section{Discussion}

An inherent feature of neurons is their ability to locally recycle the membranes of neurotransmitter containing vesicles, thus enabling uninterrupted neurotransmitter release. While exocytosis and endocytosis of synaptic vesicle precursors in immature neurons occurs at random sites along axons, following formation of axodendritic contacts synaptic vesicle precursors accumulate at these nascent synapses switching to a spatially restricted and highly regulated release of neurotransmitters, a process called "maturation" of the presynaptic vesicle release machinery (Zakharenko et al., 1999; Hata et al., 2007). In the present study we have identified NCAM as an important player in this process: it induces formation of the mature AP-2-dependent synaptic vesicle endocytotic machinery at nascent synapses.

NCAM accumulates in nascent synapses several minutes following an initial axodendritic contact (Sytnyk et al., 2002; Sytnyk et al., 2004), thus being well poised for its role in regulating synaptic transmission. Our data suggest that NCAM140 at the presynaptic membrane then recruits AP-2 and indirectly AP180 from the cytosol, thereby stabilizing these adaptors at the endocytic periactive zone. The physiological significance of this process is underscored by our observation of impaired endocytic retrieval of VAMP2, a process known to depend on AP-2/AP180 (Koo et al., 2011), in NCAM-/- neurons. We do not exclude, however, that deficiency in NCAM may also be associated with general changes in lipids/lipid dynamics in synapses, which may add to the abnormalities in synaptic vesicle recycling. The importance of the interaction between NCAM and AP-2 in endocytic retrieval of VAMP2 is supported by our data showing that
VAMP2 endocytosis is reduced in NCAM+/+ neurons overexpressing NCAM140 with a mutated binding site for AP-2 (NCAM140LA). Since NCAM140LA contains the nonmutated extracellular domain, which mediates adhesion, these data indicate that disruption of the interaction between NCAM140 and AP-2 without disruption of NCAM-dependent adhesion is sufficient to interfere with VAMP2 endocytosis.

The physiological function of NCAM detectable in synaptic vesicles (Fig. 2; Takamori et al., 2006; Morciano et al., 2009) remains to be identified. However, low levels of NCAM in synaptic vesicles support the idea that the NCAM/AP-2 complex is disassembled before synaptic vesicle endocytosis. Dissociation of the AP-2/clathrin complex from NCAM may be required to detach a nascent endocytic protein complex from the NCAMassociated spectrin cytoskeleton to allow efficient endocytosis, which is otherwise inhibited by the spectrin meshwork (Sato et al., 1995; Puchkov et al., 2011). Such a mechanism would also prevent missorting of NCAM, which instead is retained at the cell surface to promote further rounds of AP-2/AP180 recruitment at the plasma membrane. Following dissociation from NCAM, AP-2 might bind to synaptic vesicle proteins, such as synaptotagmin (Haucke and De Camilli, 1999), which transiently accumulates at the cell surface after synaptic vesicle exocytosis.

We show that AP-3 partially substitutes for AP-2 in NCAM-/- synapses. Not only the attachment of AP-3 to the membranes is increased in NCAM-/- synapses, as shown by the in vitro recruitment assay, but also the overall expression levels of AP3 are increased in NCAM-/- brains. This may explain the fact that the approximately twofold decline in AP2 levels in NCAM-/- synaptic membranes is accompanied by an approximately sixfold increase in levels of AP3. Clathrin-independent bulk endocytosis of synaptic vesicles has been observed following clathrin inactivation in Drosophila (Heerssen et al., 2008). Our data also suggest that AP-3 associates with synaptic membranes and mediates vesicle formation perhaps not only from endosomes (Faúndez et al., 1998), but also from the synaptic surface membrane, as proposed previously (Voglmaier et al., 2006). In addition to cargo-specific sorting of synaptic vesicle proteins, AP-3 promotes bulk membrane retrieval in NCAM-/- synapses, thereby compensating for AP-2 deficiency. Levels of AP-1, an adaptor protein implicated in endosomal synaptic vesicle recycling (Glyvuk et al., 2010), are also increased in NCAM-/synaptosomes and synaptic vesicles, suggesting increased synaptic vesicle recycling via endosomal intermediates.

Our data showing that AP-3 is also present at high levels in $N C A M+/+$ synapses at early stages of neuronal development confirm that AP-3 is a component of the immature synaptic vesicle endocytotic machinery. AP-3 is recruited to synaptic membranes independently of NCAM. This could be an important feature in immature axons that assures endocytosis of synaptic vesicle precursor membranes being exocytosed at random sites along axons in the absence of contacts accumulating NCAM. AP-3 mediated endocytosis is, however, less efficient, as underscored by our observations in NCAM-/- neurons and suggested previously (Voglmaier et al., 2006).

We show that with progression of brain development the immature AP-3-dependent synaptic vesicle recycling pathway is substituted by an AP-2-dependent mechanism. While the exact mechanisms underlying this switch remain to be determined, our data suggest that NCAM is one of the molecules which can induce it. In agreement, the amount of AP-2 in association with NCAM also increases with age, reflecting the increase in the ratio of mature to immature synapses. We speculate that in the absence of 


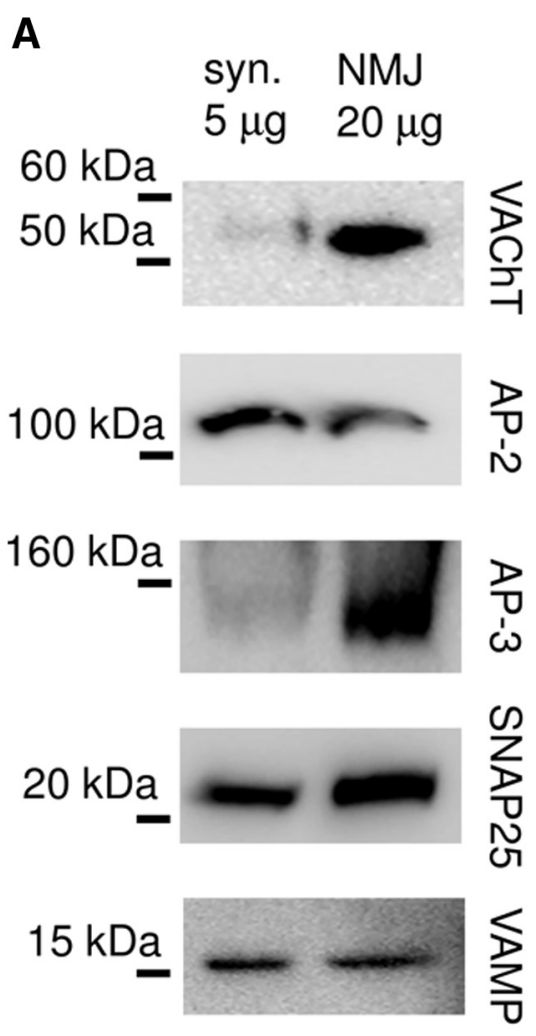

B
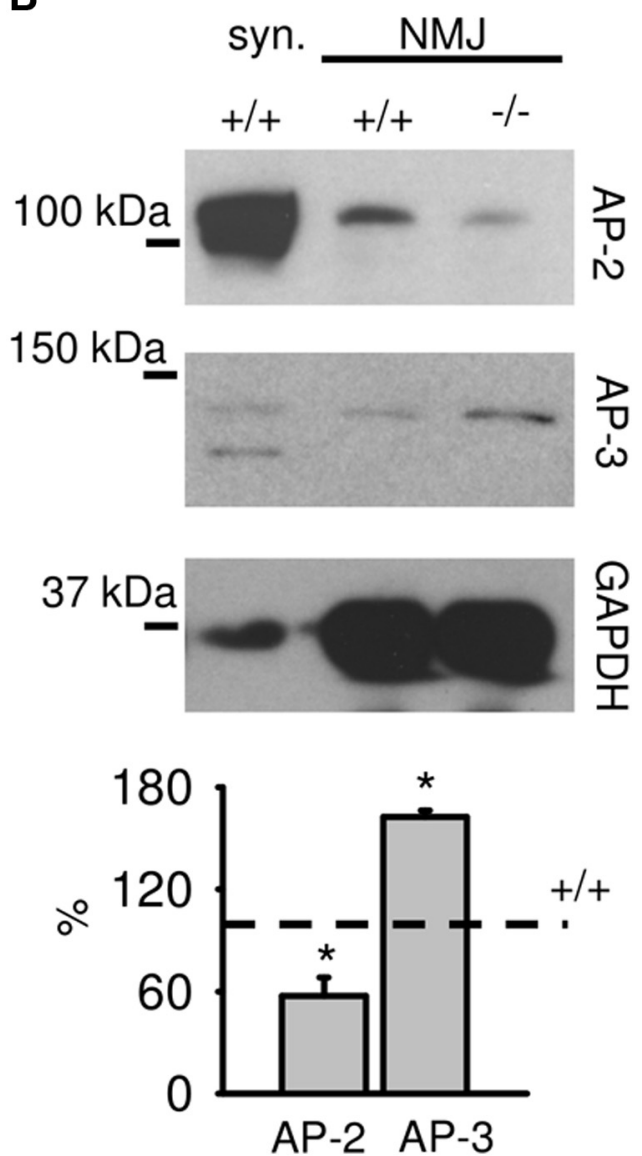

Figure 10. Stoichiometry of AP-2 and AP-3 in CNS synapses differs from the stoichiometry of these adaptor proteins in neuromuscular junctions. $A, N C A M+/+$ synaptosomes (syn.; $5 \mu \mathrm{g}$ total protein) and neuromuscular junctions (20 $\mu \mathrm{g}$ total protein) were probed by Western blot
NCAM the affinity of AP-3 to the presynaptic membrane phospholipids may be higher than that of AP-2 resulting in a predominantly AP-3-dependent mode of synaptic vesicle recycling. It is also possible that other yet unknown factors contribute to the enhanced attachment of AP-3 to NCAM-/- synaptic membranes. Binding to NCAM increases the affinity of AP-2 to the presynaptic membrane over that of AP-3 resulting in a switch from AP-3- to AP-2-dependent retrieval pathways. Interestingly, this is a reversible process, since inhibition of AP-2 binding to NCAM even in mature synaptic membranes results in a switchback to the AP-3-dependent pathway. This feature may be important for remodeling of synapses in the mature brain: synaptic vesicle clusters released from eliminated synapses or splitting from the total synaptic vesicle pool in the presynaptic boutons, the so-called "orphans" traveling and recycling along axons in the absence of a postsynaptic counterpart (Krueger et al., 2003), could then switch to the AP-3-dependent pathway upon detachment from the synaptic boutons and relocation to adjacent axonal segments with lower levels of NCAM.

Our experiments are in agreement with previous observations made in experiments with NMJs, which showed the coexistence of both immature and mature modes of synaptic vesicle recycling mechanisms in NCAM-/- NMJs (Polo-Parada et al., 2001, 2004; Hata et al., 2007). Interestingly, some of our data are in contrast to the observations in NMJs possibly reflecting differences in the overall organization of these two synapses. In particular, while BFA application to hippocampal synapses resulted in an increase in the uptake of FM1-43 into NCAM-/- synaptic boutons (Fig. 8A), BFA inhibited FM1-43 uptake in NCAM -/NMJs to $\sim 30 \%$ of that in the absence of BFA (Polo-Parada et al., 2001). A possible explanation for this difference is that the stoichiometry of AP-2 and AP-3 is different in the two types of synapses. The ratio of AP-2 to AP-3 levels in NMJs was 5.7 \pm 2.5 -fold $(n=4)$ lower than that in synaptosomes in wild-type animals (Fig. 10A). Similarly to brain synaptosomes, NCAM-/- NMJs contained higher levels of AP-3 and lower levels of AP-2 when compared to NCAM+/+ NMJs (Fig. 10B), an effect that resulted in a further reduction of AP-2 to AP-3 ratio in NCAM-/- NMJs. Hence, it is plausible that lower levels of AP-2 relative to AP-3 in NCAM $-/-$ NMJs are insufficient to fully substitute for AP-3 in the presence of BFA. However, we cannot exclude that other factors and differences in the stimulation protocols used in the FM1-43 uptake experiments may account for the observed discrepancies. Regardless of these differences, the fact that inactivation of AP-3 via application of BFA eliminated neurotransmission failures in NCAM-/- NMJs (Polo-Parada et al., 2001), while knock-down of AP-3 with siRNA also improved the efficiency of synaptic vesicle endocytosis in NCAM-/- hippocampal synapses (Figs. 8A, 9D), indicates that the immature AP-3-dependent mechanism contributes to the defects observed both in NMJs and CNS synapses.

Constitutive deficiency of the three major NCAM isoforms in mice results in abnormal emotional behavior and impaired learning

$\leftarrow$

with the indicated antibodies. Note that both preparations are positive for synaptic markers VAChT, SNAP25, and VAMP, which are present at various levels in both preparations. Note also that the levels of AP-2 relative to AP-3 are higher in synaptosomes when compared to NMJs. $\boldsymbol{B}$, $N C A M+/+$ synaptosomes (20 $\mu \mathrm{g}$ total protein) or NCAM +/+ and NCAM - / - neuromuscular junctions (20 $\mu \mathrm{g}$ total protein) were probed by Western blot with the antibodies against AP-2 and AP-3. GAPDH served as a loading control. Note that levels of AP-2 are decreased, while levels of AP-3 are increased in NCAM - / - NMJs compared to NCAM +/+ NMJs. The graph shows levels of AP-2 and AP-3 (mean + SEM) in NCAM - / - NMJs. Values were normalized to $N C A M+/+$ levels (dashed line). ${ }^{*} p<0.05$, paired $t$ test (compared to NCAM+/ $; n=3$ ). 
and memory (Cremer et al., 1994; Stork et al., 1997; Pillai-Nair et al., 2005). Mutations, abnormal processing or posttranslational modifications of NCAM lead to a number of stress-related psychiatric disorders in humans, such as mood disorders and schizophrenia (Poltorak et al., 1996; Vawter et al., 2000; Arai et al., 2004; Sandi and Bisaz, 2007; Sullivan et al., 2007; Tanaka et al., 2007). Abnormalities in neuronal network functioning have been considered as important contributors to the development of these diseases (Sandi and Bisaz, 2007). Our present findings provide insights into the molecular mechanisms that may underlie these abnormalities: inefficient endocytosis of synaptic vesicles especially under conditions of high activity accompanied by strong synapse activation and massive exocytosis of synaptic vesicles, similar to what is observed in response to high $\mathrm{K}^{+}$and electric field stimulation used in our study, may lead to inefficient recovery of synaptic vesicles and disturbances in synapse function eventually resulting in psychiatric symptoms. While further work is required to provide additional support for this idea, our data establish NCAM as an important player in the organization of the presynaptic machinery in CNS synapses.

\section{References}

Andreyeva A, Leshchyns'ka I, Knepper M, Betzel C, Redecke L, Sytnyk V, Schachner M (2010) CHL1 is a selective organizer of the presynaptic machinery chaperoning the SNARE complex. PLoS One 5:e12018. CrossRef Medline

Arai M, Itokawa M, Yamada K, Toyota T, Arai M, Haga S, Ujike H, Sora I, Ikeda K, Yoshikawa T (2004) Association of neural cell adhesion molecule 1 gene polymorphisms with bipolar affective disorder in Japanese individuals. Biol Psychiatry 55:804-810. CrossRef Medline

Araki S, Yang J, Hashiramoto M, Tamori Y, Kasuga M, Holman GD (1996) Subcellular trafficking kinetics of GLU4 mutated at the $\mathrm{N}$ - and C-terminal. Biochem J 315:153-159. Medline

Berthiaume EP, Medina C, Swanson JA (1995) Molecular size-fractionation during endocytosis in macrophages. J Cell Biol 129:989-998. CrossRef Medline

Blumstein J, Faundez V, Nakatsu F, Saito T, Ohno H, Kelly RB (2001) The neuronal form of adaptor protein-3 is required for synaptic vesicle formation from endosomes. J Neurosci 21:8034-8042. Medline

Bodrikov V, Leshchyns'ka I, Sytnyk V, Overvoorde J, den Hertog J, Schachner M (2005) RPTPalpha is essential for NCAM-mediated p59fyn activation and neurite elongation. J Cell Biol 168:127-139. Medline

Bonanomi D, Benfenati F, Valtorta F (2006) Protein sorting in the synaptic vesicle life cycle. Prog Neurobiol 80:177-217. CrossRef Medline

Chernyshova Y, Leshchyns'ka I, Hsu SC, Schachner M, Sytnyk V (2011) The neural cell adhesion molecule promotes FGFR-dependent phosphorylation and membrane targeting of the exocyst complex to induce exocytosis in growth cones. J Neurosci 31:3522-3535. CrossRef Medline

Cheung G, Cousin MA (2012) Adaptor protein complexes 1 and 3 are essential for generation of synaptic vesicles from activity-dependent bulk endosomes. J Neurosci 32:6014-6023. CrossRef Medline

Cheung G, Jupp OJ, Cousin MA (2010) Activity-dependent bulk endocytosis and clathrin-dependent endocytosis replenish specific synaptic vesicle pools in central nerve terminals. J Neurosci 30:8151-8161. CrossRef Medline

Cremer H, Lange R, Christoph A, Plomann M, Vopper G, Roes J, Brown R, Baldwin S, Kraemer P, Scheff S, Barthels D, Rajewsky K, Wille W (1994) Inactivation of the N-CAM gene in mice results in size reduction of the olfactory bulb and deficits in spatial learning. Nature 367:455-459. CrossRef Medline

Dityatev A, Schachner M, Sonderegger P (2010a) The dual role of the extracellular matrix in synaptic plasticity and homeostasis. Nat Rev Neurosci 11:735-746. CrossRef Medline

Dityatev A, Seidenbecher CI, Schachner M (2010b) Compartmentalization from the outside: the extracellular matrix and functional microdomains in the brain. Trends Neurosci 33:503-512. CrossRef Medline

Faúndez V, Horng JT, Kelly RB (1998) A function for the AP3 coat complex in synaptic vesicle formation from endosomes. Cell 93:423-432. CrossRef Medline

Ford MG, Pearse BM, Higgins MK, Vallis Y, Owen DJ, Gibson A, Hopkins
CR, Evans PR, McMahon HT (2001) Simultaneous binding of PtdIns(4,5)P2 and clathrin by AP180 in the nucleation of clathrin lattices on membranes. Science 291:1051-1055. CrossRef Medline

Fux CM, Krug M, Dityatev A, Schuster T, Schachner M (2003) NCAM180 and glutamate receptor subtypes in potentiated spine synapses: an immunogold electron microscopic study. Mol Cell Neurosci 24:939-950. CrossRef Medline

Gerrow K, El-Husseini A (2006) Cell adhesion molecules at the synapse. Front Biosci 11:2400-2419. CrossRef Medline

Glyvuk N, Tsytsyura Y, Geumann C, D’Hooge R, HüveJ, Kratzke M, Baltes J, Böning D, Klingauf J, Schu P (2010) AP-1/sigma1B-adaptin mediates endosomal synaptic vesicle recycling, learning and memory. EMBO J 29: 1318-1330. CrossRef Medline

Hannah MJ, Schmidt AA, Huttner WB (1999) Synaptic vesicle biogenesis. Annu Rev Cell Dev Biol 15:733-798. CrossRef Medline

Hao W, Luo Z, Zheng L, Prasad K, Lafer EM (1999) AP180 and AP-2 interact directly in a complex that cooperatively assembles clathrin. J Biol Chem 274:22785-22794. CrossRef Medline

Hata K, Polo-Parada L, Landmesser LT (2007) Selective targeting of different neural cell adhesion molecule isoforms during motoneuron myotube synapse formation in culture and the switch from an immature to mature form of synaptic vesicle cycling. J Neurosci 27:14481-14493. CrossRef Medline

Haucke V, De Camilli P (1999) AP-2 recruitment to synaptotagmin stimulated by tyrosine-based endocytic motifs. Science 285:1268-1271. CrossRef Medline

Heerssen H, Fetter RD, Davis GW (2008) Clathrin dependence of synapticvesicle formation at the Drosophila neuromuscular junction. Curr Biol 18:401-409. CrossRef Medline

Hill E, van Der Kaay J, Downes CP, Smythe E (2001) The role of dynamin and its binding partners in coated pit invagination and scission. J Cell Biol 152:309-323. CrossRef Medline

Holt M, Cooke A, Wu MM, Lagnado L (2003) Bulk membrane retrieval in the synaptic terminal of retinal bipolar cells. J Neurosci 23:1329-1339. Medline

Huttner WB, Schiebler W, Greengard P, De Camilli P (1983) Synapsin I (protein I), a nerve terminal-specific phosphoprotein. III. Its association with synaptic vesicles studied in a highly purified synaptic vesicle preparation. J Cell Biol 96:1374-1388. CrossRef Medline

Kantheti P, Qiao X, Diaz ME, Peden AA, Meyer GE, Carskadon SL, Kapfhamer D, Sufalko D, Robinson MS, Noebels JL, Burmeister M (1998) Mutation in AP-3 delta in the mocha mouse links endosomal transport to storage deficiency in platelets, melanosomes, and synaptic vesicles. Neuron 21:111-122. CrossRef Medline

Kim SH, Ryan TA (2009) Synaptic vesicle recycling at CNS snapses without AP-2. J Neurosci 29:3865-3874. CrossRef Medline

Kleene R, Yang H, Kutsche M, Schachner M (2001) The neural recognition molecule L1 is a sialic acid-binding lectin for CD24, which induces promotion and inhibition of neurite outgrowth. J Biol Chem 276:2165621663. CrossRef Medline

Koo SJ, Markovic S, Puchkov D, Mahrenholz CC, Beceren-Braun F, Maritzen T, Dernedde J, Volkmer R, Oschkinat H, Haucke V (2011) SNARE motif-mediated sorting of synaptobrevin by the endocytic adaptors clathrin assembly lymphoid myeloid leukemia (CALM) and AP180 at synapses. Proc Natl Acad Sci U S A 108:13540-13545. CrossRef Medline

Krauss M, Kinuta M, Wenk MR, De Camilli P, Takei K, Haucke V (2003) ARF6 stimulates clathrin/AP-2 recruitment to synaptic membranes by activating phosphatidylinositol phosphate kinase type Igamma. J Cell Biol 162:113-124. CrossRef Medline

Krueger SR, Kolar A, Fitzsimonds RM (2003) The presynaptic release apparatus is functional in the absence of dendritic contact and highly mobile within isolated axons. Neuron 40:945-957. CrossRef Medline

Leshchyns'ka I, Sytnyk V, Morrow JS, Schachner M (2003) Neural cell adhesion molecule (NCAM) association with PKCbeta2 via betaI spectrin is implicated in NCAM-mediated neurite outgrowth. J Cell Biol 161:625639. CrossRef Medline

Leshchyns'ka I, Sytnyk V, Richter M, Andreyeva A, Puchkov D, Schachner M (2006) The adhesion molecule CHL1 regulates uncoating of clathrincoated synaptic vesicles. Neuron 52:1011-1025. CrossRef Medline

Leshchyns'ka I, Tanaka MM, Schachner M, Sytnyk V (2011) Immobilized pool of NCAM180 in the postsynaptic membrane is homeostatically re- 
plenished by the flux of NCAM180 from extrasynaptic regions. J Biol Chem 286:23397-23406. CrossRef Medline

Li S, Leshchyns'ka I, Chernyshova Y, Schachner M, Sytnyk V (2013) The neural cell adhesion molecule (NCAM) associates with and signals through p21-activated kinase 1 (Pak1). J Neurosci 33:790-803. CrossRef Medline

Miesenböck G, De Angelis DA, Rothman JE (1998) Visualizing secretion and synaptic transmission with $\mathrm{pH}$-sensitive green fluorescent proteins. Nature 394:192-195. CrossRef Medline

Morciano M, Beckhaus T, Karas M, Zimmermann H, Volknandt W (2009) The proteome of the presynaptic active zone: from docked synaptic vesicles to adhesion molecules and maxi-channels. J Neurochem 108:662675. CrossRef Medline

Mousavi SA, Malerød L, Berg T, Kjeken R (2004) Clathrin-dependent endocytosis. Biochem J 377:1-16. CrossRef Medline

Nakatsu F, Okada M, Mori F, Kumazawa N, Iwasa H, Zhu G, Kasagi Y, Kamiya H, Harada A, Nishimura K, Takeuchi A, Miyazaki T, Watanabe M, Yuasa S, Manabe T, Wakabayashi K, Kaneko S, Saito T, Ohno H (2004) Defective function of GABA-containing synaptic vesicles in mice lacking the AP-3B clathrin adaptor. J Cell Biol 167:293-302. CrossRef Medline

Neale EA, Bowers LM, Jia M, Bateman KE, Williamson LC (1999) Botulinum neurotoxin A blocks synaptic vesicle exocytosis but not endocytosis at the nerve terminal. J Cell Biol 147:1249-1260. CrossRef Medline

Newman LS, McKeever MO, Okano HJ, Darnell RB (1995) Beta-NAP, a cerebellar degeneration antigen, is a neuron-specific vesicle coat protein. Cell 82:773-783. CrossRef Medline

Newton AJ, Kirchhausen T, Murthy VN (2006) Inhibition of dynamin completely blocks compensatory synaptic vesicle endocytosis. Proc Natl Acad Sci U S A 103:17955-17960. CrossRef Medline

Ooi CE, Dell'Angelica EC, Bonifacino JS (1998) ADP-Ribosylation factor 1 (ARF1) regulates recruitment of the AP-3 adaptor complex to membranes. J Cell Biol 142:391-402. CrossRef Medline

Persohn E, Schachner M (1987) Immunoelectron microscopic localization of the neural cell adhesion molecules L1 and N-CAM during postnatal development of the mouse cerebellum. J Cell Biol 105:569-576. CrossRef Medline

Persohn E, Pollerberg GE, Schachner M (1989) Immunoelectronmicroscopic localization of the $180 \mathrm{kD}$ component of the neural cell adhesion molecule N-CAM in postsynaptic membranes. J Comp Neurol 288:92-100. CrossRef Medline

Pillai-Nair N, Panicker AK, Rodriguiz RM, Gilmore KL, Demyanenko GP, Huang JZ, Wetsel WC, Maness PF (2005) Neural cell adhesion molecule-secreting transgenic mice display abnormalities in GABAergic interneurons and alterations in behavior. J Neurosci 25:4659-4671. CrossRef Medline

Pollerberg EG, Sadoul R, Goridis C, Schachner M (1985) Selective expression of the $180-\mathrm{kD}$ component of the neural cell adhesion molecule N-CAM during development. J Cell Biol 101:1921-1929. CrossRef Medline

Pollerberg GE, Schachner M, Davoust J (1986) Differentiation statedependent surface mobilities of two forms of the neural cell adhesion molecule. Nature 324:462-465. CrossRef Medline

Polo-Parada L, Bose CM, Landmesser LT (2001) Alterations in transmission, vesicle dynamics, and transmitter release machinery at NCAMdeficient neuromuscular junctions. Neuron 32:815-828. CrossRef Medline

Polo-Parada L, Bose CM, Plattner F, Landmesser LT (2004) Distinct roles of different neural cell adhesion molecule (NCAM) isoforms in synaptic maturation revealed by analysis of NCAM $180 \mathrm{kDa}$ isoform-deficient mice. J Neurosci 24:1852-1864. CrossRef Medline

Poltorak M, Frye MA, Wright R, Hemperly JJ, George MS, Pazzaglia PJ, Jerrels SA, Post RM, Freed WJ (1996) Increased neural cell adhesion molecule in the CSF of patients with mood disorder. J Neurochem 66:1532-1538. Medline

Puchkov D, Leshchyns'ka I, Nikonenko AG, Schachner M, Sytnyk V (2011) NCAM/spectrin complex disassembly results in PSD perforation and postsynaptic endocytic zone formation. Cereb Cortex 21:2217-2232. CrossRef Medline

Robineau S, Chabre M, Antonny B (2000) Binding site of brefeldin A at the interface between the small G protein ADP-ribosylation factor 1 (ARF1) and the nucleotide-exchange factor Sec7 domain. Proc Natl Acad Sci U S A 97:9913-9918. CrossRef Medline

Rolf B, Lang D, Hillenbrand R, Richter M, Schachner M, Bartsch U (2003) Altered expression of CHL1 by glial cells in response to optic nerve injury and intravitreal application of fibroblast growth factor-2. J Neurosci Res 71:835-843. CrossRef Medline

Salazar G, Love R, Styers ML, Werner E, Peden A, Rodriguez S, Gearing M, Wainer BH, Faundez V (2004) AP-3-dependent mechanisms control the targeting of a chloride channel (ClC-3) in neuronal and non-neuronal cells. J Biol Chem 279:25430-25439. CrossRef Medline

Salem N, Faúndez V, Horng JT, Kelly RB (1998) A v-SNARE participates in synaptic vesicle formation mediated by the AP3 adaptor complex. Nat Neurosci 1:551-556. CrossRef Medline

Sandi C, Bisaz R (2007) A model for the involvement of neural cell adhesion molecules in stress-related mood disorders. Neuroendocrinology 85: 158-176. CrossRef Medline

Santuccione A, Sytnyk V, Leshchyns'ka I, Schachner M (2005) Prion protein recruits its neuronal receptor NCAM to lipid rafts to activate p59fyn and to enhance neurite outgrowth. J Cell Biol 169:341-354. CrossRef Medline

Sato K, Saito Y, Kawashima S (1995) Identification and characterization of membrane-bound calpains in clathrin-coated vesicles from bovine brain. Eur J Biochem 230:25-31. CrossRef Medline

Schuster T, Krug M, Stalder M, Hackel N, Gerardy-Schahn R, Schachner M (2001) Immunoelectron microscopic localization of the neural recognition molecules L1, NCAM, and its isoform NCAM180, the NCAMassociated polysialic acid, betal integrin and the extracellular matrix molecule tenascin-R in synapses of the adult rat hippocampus. J Neurobiol 49:142-158. CrossRef Medline

Seong E, Wainer BH, Hughes ED, Saunders TL, Burmeister M, Faundez V (2005) Genetic analysis of the neuronal and ubiquitous AP-3 adaptor complexes reveals divergent functions in brain. Mol Biol Cell 16:128-140. Medline

Shen K, Scheiffele P (2010) Genetics and cell biology of building specific synaptic connectivity. Annu Rev Neurosci 33:473-507. CrossRef Medline

Shi G, Faúndez V, Roos J, Dell'Angelica EC, Kelly RB (1998) Neuroendocrine synaptic vesicles are formed in vitro by both clathrin-dependent and clathrin-independent pathways. J Cell Biol 143:947-955. CrossRef Medline

Slepnev VI, De Camilli P (2000) Accessory factors in clathrin-dependent synaptic vesicle endocytosis. Nat Rev Neurosci 1:161-172. CrossRef Medline

Stork O, Welzl H, Cremer H, Schachner M (1997) Increased intermale aggression and neuroendocrine response in mice deficient for the neural cell adhesion molecule (NCAM). Eur J Neurosci 9:1117-1125. CrossRef Medline

Südhof TC (2008) Neuroligins and neurexins link synaptic function to cognitive disease. Nature 455:903-911. CrossRef Medline

Sullivan PF, Keefe RS, Lange LA, Lange EM, Stroup TS, Lieberman J, Maness PF (2007) NCAM1 and neurocognition in schizophrenia. Biol Psychiatry 61:902-910. CrossRef Medline

Sytnyk V, Leshchyns'ka I, Delling M, Dityateva G, Dityatev A, Schachner M (2002) Neural cell adhesion molecule promotes accumulation of TGN organelles at sites of neuron-to-neuron contacts. J Cell Biol 159:649-661. CrossRef Medline

Sytnyk V, Leshchyns'ka I, Dityatev A, Schachner M (2004) Trans-Golgi network delivery of synaptic proteins in synaptogenesis. J Cell Sci 117:381388. Medline

Sytnyk V, Leshchyns'ka I, Nikonenko AG, Schachner M (2006) NCAM promotes assembly and activity-dependent remodeling of the postsynaptic signaling complex. J Cell Biol 174:1071-1085. CrossRef Medline

Takamori S, Holt M, Stenius K, Lemke EA, Grønborg M, Riedel D, Urlaub H, Schenck S, Brügger B, Ringler P, Müller SA, Rammner B, Gräter F, Hub JS, De Groot BL, Mieskes G, Moriyama Y, Klingauf J, Grubmüller H, Heuser J, et al. (2006) Molecular anatomy of a trafficking organelle. Cell 127:831-846. CrossRef Medline

Tanaka Y, Yoshida S, Shimada Y, Ueda H, Asai K (2007) Alteration in serum neural cell adhesion molecule in patients of schizophrenia. Hum Psychopharmacol 22:97-102. CrossRef Medline

Teng H, Wilkinson RS (2000) Clathrin-mediated endocytosis near active zones in snake motor boutons. J Neurosci 20:7986-7993. Medline

Thoidis G, Chen P, Pushkin AV, Vallega G, Leeman SE, Fine RE, Kandror KV 
(1998) Two distinct populations of synaptic-like vesicles from rat brain. Proc Natl Acad Sci U S A 95:183-188. CrossRef Medline

Vawter MP, Frye MA, Hemperly JJ, VanderPutten DM, Usen N, Doherty P, Saffell JL, Issa F, Post RM, Wyatt RJ, Freed WJ (2000) Elevated concentration of N-CAM VASE isoforms in schizophrenia. J Psychiatr Res 34: 25-34. CrossRef Medline

Virmani T, Han W, Liu X, Südhof TC, Kavalali ET (2003) Synaptotagmin 7 splice variants differentially regulate synaptic vesicle recycling. EMBO J 22:5347-5357. CrossRef Medline

Voglmaier SM, Kam K, Yang H, Fortin DL, Hua Z, Nicoll RA, Edwards RH (2006) Distinct endocytic pathways control the rate and extent of synaptic vesicle protein recycling. Neuron 51:71-84. CrossRef Medline

Westphal D, Sytnyk V, Schachner M, Leshchyns'ka I (2010) Clustering of the neural cell adhesion molecule (NCAM) at the neuronal cell surface induces caspase-8- and -3-dependent changes of the spectrin meshwork required for NCAM-mediated neurite outgrowth. J Biol Chem 285: 42046-42057. CrossRef Medline
Whelchel DD, Brehmer TM, Brooks PM, Darragh N, Coffield JA (2004) Molecular targets of botulinum toxin at the mammalian neuromuscular junction. Mov Disord 19:S7-S16. CrossRef Medline

Whittaker VP, Barker LA (1972) The subcellular fractionation of brain tissue with special reference to the preparation of synaptosomes and their component organelles. In: Methods of neurochemistry (Fried R, ed), pp 1-52. New York: Dekker.

Zakharenko S, Chang S, O'Donoghue M, Popov SV (1999) Neurotransmitter secretion along growing nerve processes: comparison with synaptic vesicle exocytosis. J Cell Biol 144:507-518. CrossRef Medline

Zhang B, Koh YH, Beckstead RB, Budnik V, Ganetzky B, Bellen HJ (1998) Synaptic vesicle size and number are regulated by a clathrin adaptor protein required for endocytosis. Neuron 21:1465-1475. CrossRef Medline

Zhang JZ, Davletov BA, Südhof TC, Anderson RG (1994) Synaptotagmin I is a high affinity receptor for clathrin AP-2: implications for membrane recycling. Cell 78:751-760. CrossRef Medline 